\title{
Functional genomics and expression analysis of the Corynebacterium glutamicum fpr2-cysIXHDNYZ gene cluster involved in assimilatory
} sulphate reduction

\author{
Christian Rückert ${ }^{1,2}$, Daniel J Koch 1,2, Daniel A Rey², Andreas Albersmeier², \\ Sascha Mormann ${ }^{2}$, Alfred Pühler ${ }^{3}$ and Jörn Kalinowski*2
}

Address: ${ }^{1}$ International NRW Graduate School in Bioinformatics \& Genome Research, Universität Bielefeld, D-33594 Bielefeld, Germany, ${ }^{2}$ Institut für Genomforschung, Universität Bielefeld, D-33594 Bielefeld, Germany and ${ }^{3}$ Lehrstuhl für Genetik, Universität Bielefeld, D-33594 Bielefeld, Germany

Email: Christian Rückert - cruecker@genetik.uni-bielefeld.de; Daniel J Koch - dkoch@genetik.uni-bielefeld.de; Daniel A Rey - daniel.rey@genetik.uni-bielefeld.de; Andreas Albersmeier - aalbersm@genetik.uni-bielefeld.de; Sascha Mormann - smormann@genetik.uni-bielefeld.de; Alfred Pühler - puehler@genetik.uni-bielefeld.de; Jörn Kalinowski* - joern.kalinowski@genetik.uni-bielefeld.de

* Corresponding author

Published: 13 September 2005

BMC Genomics 2005, 6:121 doi:10.1|86/147|-2|64-6-12|
Received: 22 June 2005

Accepted: 13 September 2005

This article is available from: http://www.biomedcentral.com/l47I-2164/6/121

(c) 2005 Rückert et al; licensee BioMed Central Ltd.

This is an Open Access article distributed under the terms of the Creative Commons Attribution License (http://creativecommons.org/licenses/by/2.0), which permits unrestricted use, distribution, and reproduction in any medium, provided the original work is properly cited.

\begin{abstract}
Background: Corynebacterium glutamicum is a high-GC Gram-positive soil bacterium of great biotechnological importance for the production of amino acids. To facilitate the rational design of sulphur amino acid-producing strains, the pathway for assimilatory sulphate reduction providing the necessary reduced sulfur moieties has to be known. Although this pathway has been well studied in Gram-negative bacteria like Escherichia coli and low-GC Gram-positives like Bacillus subtilis, little is known for the Actinomycetales and other high-GC Gram-positive bacteria.
\end{abstract}

Results: The genome sequence of $C$. glutamicum was searched for genes involved in the assimilatory reduction of inorganic sulphur compounds. A cluster of eight candidate genes could be identified by combining sequence similarity searches with a subsequent synteny analysis between $C$. glutamicum and the closely related $C$. efficiens. Using mutational analysis, seven of the eight candidate genes, namely cys $Z$, cys $Y, c y s N, c y s D, c y s H, c y s X$, and cysl, were demonstrated to be involved in the reduction of inorganic sulphur compounds. For three of the up to now unknown genes possible functions could be proposed: CysZ is likely to be the sulphate permease, while $\mathrm{Cys} X$ and $\mathrm{Cys} Y$ are possibly involved in electron transfer and cofactor biosynthesis, respectively. Finally, the candidate gene designated fpr 2 influences sulphur utilisation only weakly and might be involved in electron transport for the reduction of sulphite. Real-time RT-PCR experiments revealed that cysIXHDNYZ form an operon and that transcription of the extended cluster fpr2 cysIXHDNYZ is strongly influenced by the availability of inorganic sulphur, as well as L-cysteine. Mapping of the $f p r 2$ and cysIXHDNYZ promoters using RACE-PCR indicated that both promoters overlap with binding-sites of the transcriptional repressor McbR, suggesting an involvement of McbR in the observed regulation. Comparative genomics revealed that large parts of the extended cluster are conserved in II of 17 completely sequenced members of the Actinomycetales.

Conclusion: The set of $C$. glutamicum genes involved in assimilatory sulphate reduction was identified and four novel genes involved in this pathway were found. The high degree of conservation of this cluster among the Actinomycetales supports the hypothesis that a different metabolic pathway for the reduction of inorganic sulphur compounds than that known from the well-studied model organisms $E$. coli and $B$. subtilis is used by members of this order, providing the basis for further biochemical studies. 


\section{Background}

In many micro-organisms as well as in higher plants the metabolism of sulphur is based on the uptake and subsequent reduction of oxidised, inorganic sulphur compounds, usually sulphate. While this pathway has been studied in detail in the model organisms Escherichia coli for the Gram-negative bacteria [1] and Bacillus subtilis for the Firmicutes (low-GC Gram-positives), almost no data is available for the high-GC Gram-positives of the order Actinomycetales with the exception of the functional analysis of cysH from Mycobacterium tuberculosis [2].

The pathway for assimilatory sulphate reduction and its genetic basis in E. coli and B. subtilis can be summarised as follows: After uptake through either an ABC-type transporter, in E. coli encoded by $s b p$ [EMBL:AAC76899] and cysUWA [EMBL:AAC75477, EMBL:AAC75476, EMBL:AAC75475] [1] or, in B. subtilis, a permease encoded by cysP [EMBL:CAB13432] [3], reduction of inorganic sulphate starts with the activation of sulphate by adenylylation, catalyzed by sulphate adenylyltransferase (EC 2.7.7.4), and yielding adenylylsulphate (APS). In $E$. coli this enzyme is a heteromer encoded by $c y s D$ and $c y s \mathrm{~N}$ [EMBL:AAC75794, EMBL:AAC75793] while B. subtilis uses the homomeric protein Sat [EMBL:CAB13437] (encoded by $y \ln B$ ) which is known in other organisms to be involved in dissimilatory sulphate reduction [4]. The release of sulphite from APS can occur either by direct reduction through APS reductase (CysH, EC 1.8.4.10) or by APS kinase (CysC, EC 2.7.1.25) mediated phosphorylation and subsequent reduction of the product, phosphoadenylylsulphate (PAPS), by PAPS reductase (CysH, EC 1.8.4.8). E. coli has been demonstrated to use the twostep reaction via CysHC [EMBL:AAC75804, EMBL:AAC75792] while B. subtilis CysH [EMBL:CAB13431] can also directly convert APS to sulphite [5]. In either case, sulphite is then reduced to sulphide by sulphite reductase (CysIJ [EMBL:AAC75805, EMBL:AAC75806], EC 1.8.1.2) [6]. In addition to the enzymes directly involved in the catalysis, two additional proteins are thought to be necessary for sulphate reduction in E. coli: uroporphyrin-III C-methyltransferase (CysG [EMBL:AAC76393], EC 2.1.1.107) and PAPS phosphatase (CysQ [EMBL:AAC77171]). The former is needed for the biosynthesis of the sulphite reductase cofactor siroheme, catalyzed by YlnD [EMBL:CAB13435] and YlnF [EMBL:CAB13437] in B. subtilis [7], while the latter is believed to eliminate excess amounts of PAPS which are highly toxic for the cell [1].

In a continuation of our work to elucidate the biosynthesis of L-methionine in the Gram-positive non-sporulating actinobacterium Corynebacterium glutamicum [8], the reduction of inorganic sulphur compounds was investigated in order to learn how the reduced sulphur needed for incorporation into L-methionine is formed. Based on the knowledge of assimilatory sulphur reduction and the genes described for the two model organisms E. coli and $B$. subtilis, we tried to identify the set of genes involved in the assimilatory reduction of inorganic, oxidised sulphur compounds in C. glutamicum. Real-time RT-PCR was then applied to analyse the operon structure of the genes found and to elucidate their regulation in cells incubated with different sulphur sources. Subsequently, RACE-PCR was used to map the transcription start points of the identified transcription units to identify the potential promoters. Finally, comparison with other completely sequenced members of the Actinomycetales was carried out in order to learn about the phylogenetic distribution of the assimilatory sulphur reduction genes.

\section{Results \\ Identification of a Corynebacterium glutamicum gene cluster possibly involved in assimilatory sulphate reduction by sequence similarity and comparative genomics}

In a previous investigation, the whole genome sequence of C. glutamicum $[9,10]$ was used to elucidate the pathway for L-methionine biosynthesis [8]. In this study, we extended this work and analysed the genetic basis for the reduction of inorganic sulphate. Using genes known to be involved in the assimilatory reduction of sulphate from Escherichia coli [1], Mycobacterium tuberculosis [2], and Bacillus subtilis $[3,7,11]$ similar coding sequences (CDS) were searched for in the C. glutamicum genome sequence.

This approach led to the identification of a cluster of four CDS (cg3118, cg3116, cg3115, and cg3114 ) in C. glutamicum which might be the orthologues of the $E$. coli genes $c y s I, c y s H, c y s D$, and $c y s N$ (Table 1 and Figure 1), while no genes with high similarity to the E. coli genes $c y s C, c y s J, s b p$ or the cysPUWA cluster could be found (data not shown). Likewise, no clear homologues of the $B$. subtilis genes $c y s P$ or $y \ln B$ were detected. Closer examination of the genomic neighbourhood of the four candidate genes revealed another three CDS which are located within (cg3117) or directly adjacent $(\operatorname{cg} 3112, \operatorname{cg} 3113)$ to the identified cluster of $c y s$ genes. To determine the boundaries of this cluster, all genes in this genomic region were compared with the genome of the closely related species Corynebacterium efficiens [12], using a bidirectional best BLAST hit method [13].

Thereby it could be shown that besides the identified $c y s$ orthologues, the localisation of cg3112, cg3113, and cg3117 is also well conserved between C. glutamicum and C. efficiens, as is that of cg3119 while directly up- and downstream of the cluster the syntenous order of genes is interrupted by insertions in C. glutamicum (data not shown). The notion that the $c y s$ gene-cluster extends from cg3112 to cg3119 is corroborated by the finding that 
Table I: Properties and sequence similarities of the $C$. glutamicum proteins possibly involved in assimilatory reduction of sulphate

\begin{tabular}{|c|c|c|c|c|c|c|c|c|}
\hline \multirow{2}{*}{$\begin{array}{l}\text { C. glutamicum } \\
\text { CDS (protein }{ }^{a} \text { ) }\end{array}$} & \multicolumn{3}{|c|}{ protein properties } & \multirow[b]{2}{*}{ hit against } & \multicolumn{3}{|c|}{ BLAST results ${ }^{b}$} & \multirow[b]{2}{*}{$\begin{array}{l}\text { identical/ } \\
\text { positive aa }\end{array}$} \\
\hline & length $(a a)$ & $\mathrm{pl}$ & $\mathrm{mw}[\mathrm{kDa}]$ & & in organismc & description & E-value & \\
\hline \multirow[t]{3}{*}{ Cg3II2 (CysZ) } & 309 & 9.98 & 32.0 & Q8FM69 & C. efficiens & $\begin{array}{l}\text { Conserved hypothetical } \\
\text { protein }\end{array}$ & $2 \mathrm{e}-134$ & $77 / 88 \%$ \\
\hline & & & & Q8INU8 & B. anthracis & Putative membrane protein & $8 e-58$ & $46 / 64 \%$ \\
\hline & & & & Q8I3F4 & B. cereus & $\begin{array}{l}\text { Hypothetical membrane } \\
\text { spanning protein }\end{array}$ & $4 e-57$ & $46 / 64 \%$ \\
\hline \multirow[t]{3}{*}{ Cg3III (CysY) } & 241 & 5.44 & 24.7 & Q8FM68 & C. efficiens & Hypothetical protein & le-80 & $67 / 77 \%$ \\
\hline & & & & P61817 & B. megaterium & $\begin{array}{l}\text { Sirohydrochlorin } \\
\text { ferrochelatase SirB }\end{array}$ & $5 e-16$ & $28 / 45 \%$ \\
\hline & & & & Q93RW8 & S. coelicolor & $\begin{array}{l}\text { Hypothetical protein } \\
\text { SC01858 }\end{array}$ & $2 \mathrm{e}-13$ & $31 / 43 \%$ \\
\hline \multirow[t]{3}{*}{$\mathrm{Cg} 3 \mathrm{II} 4(\mathrm{Cys} \mathrm{N})$} & 433 & 5.08 & 46.9 & Q8FM67 & C. efficiens & $\begin{array}{l}\text { Putative sulphate } \\
\text { adenylyltransferase SU I }\end{array}$ & 0.0 & $84 / 90 \%$ \\
\hline & & & & Q9ADG6 & S. coelicolor & $\begin{array}{l}\text { Sulphate adenylyltransferase } \\
\text { SU I }\end{array}$ & $3 e-111$ & $55 / 67 \%$ \\
\hline & & & & Q10600 & M. tuberculosis & $\begin{array}{l}\text { Sulphate adenylyltransferase } \\
\text { SU I }\end{array}$ & le-104 & $50 / 69 \%$ \\
\hline \multirow[t]{3}{*}{ Cg3III (CysD) } & 304 & 5.09 & 34.3 & Q8FM66 & C. efficiens & $\begin{array}{l}\text { Putative sulphate } \\
\text { adenylyltransferase }\end{array}$ & $7 e-168$ & $95 / 96 \%$ \\
\hline & & & & Q9ADG5 & S. coelicolor & $\begin{array}{l}\text { Sulphate adenylyltransferase } \\
\text { SU } 2\end{array}$ & $2 \mathrm{e}-123$ & $71 / 83 \%$ \\
\hline & & & & Q9X5UO & S. lavendulae & $\begin{array}{l}\text { Sulphate adenylyltransferase } \\
\text { SU } 2\end{array}$ & $6 e-123$ & $70 / 82 \%$ \\
\hline \multirow[t]{3}{*}{$\mathrm{Cg} 3 \mathrm{II} 6(\mathrm{CysH})$} & 261 & 5.30 & 28.5 & Q8FM65 & C. efficiens & Putative PAPS reductase & $3 e-129$ & $86 / 89 \%$ \\
\hline & & & & Q82L82 & S. avermitilis & Putative PAPS reductase & $7 e-52$ & $56 / 67 \%$ \\
\hline & & & & P7I 752 & M. tuberculosis & APS reductase & $5 e-52$ & $54 / 69 \%$ \\
\hline \multirow[t]{3}{*}{ Cg3II7 (CysX) } & 82 & 7.86 & 9.5 & Q8FM64 & C. efficiens & Hypothetical protein & $5 e-36$ & $81 / 89 \%$ \\
\hline & & & & Q82L83 & S. avermitilis & Hypothetical protein & $4 e-05$ & $50 / 57 \%$ \\
\hline & & & & Q9ADG2 & S. coelicolor & $\begin{array}{l}\text { Hypothetical protein } \\
\text { SC0610I }\end{array}$ & $5 e-05$ & $50 / 57 \%$ \\
\hline \multirow[t]{3}{*}{ Cg3II8 (Cysl) } & 561 & 5.53 & 63.0 & Q8FM63 & C. efficiens & $\begin{array}{l}\text { Putative ferredoxin-nitrite } \\
\text { reductase }\end{array}$ & 0.0 & $91 / 95 \%$ \\
\hline & & & & Q7WT38 & Streptomyces sp. & Nitrile/sulphite reductase & 0.0 & $56 / 70 \%$ \\
\hline & & & & Q82L84 & S. avermitilis & $\begin{array}{l}\text { Putative nitrile/sulphite } \\
\text { reductase }\end{array}$ & 0.0 & $55 / 71 \%$ \\
\hline \multirow[t]{5}{*}{ Cg31I9 (Fpr2) } & 457 & 4.88 & 50.1 & Q8FM62 & C. efficiens & $\begin{array}{l}\text { Putative ferredoxin-NADP } \\
\text { reductase }\end{array}$ & 0.0 & $87 / 93 \%$ \\
\hline & & & & Q8NM28 & C. glutamicum & $\begin{array}{l}\text { NADPH-glutamate synthase } \\
\text { beta chain }\end{array}$ & 0.0 & $74 / 86 \%$ \\
\hline & & & & Q8FMB5 & C. efficiens & $\begin{array}{l}\text { Putative ferredoxin/ } \\
\text { adrenodoxin reductase }\end{array}$ & 0.0 & $75 / 85 \%$ \\
\hline & & & & FPRA_MYCTU & M. tuberculosis & $\begin{array}{l}\text { Ferredoxin-NADP reductase } \\
\text { FprA }\end{array}$ & $6 e-83$ & $39 \%$ \\
\hline & & & & FPRB_MYCTU & M. tuberculosis & $\begin{array}{l}\text { Ferredoxin-NADP reductase } \\
\text { FprB }\end{array}$ & $63 e-66$ & $36 \%$ \\
\hline
\end{tabular}

$a$ by sequence similarity

$b$ identified by BLASTP similarity search. The protein sequences derived from the $C$. glutamicum candidate CDS were used as queries against the UniProt database

${ }^{c} B$. $=$ Bacillus, $C .=$ Corynebacterium, $M .=$ Mycobacterium, $S$. = Streptomyces

transcriptional termination signals were predicted by the TransTerm software [14] directly behind cg3112 and cg3119 (Fig. 1). This furthermore suggests that $c g 3118$ to cg3112 form an operon, providing another hint that also cg3112, cg3113, and cg3117 are involved in the reduction of sulphate. Additional evidence that the whole cluster is involved in sulphur metabolism was the identification of four binding sites of the transcriptional repressor McbR which controls almost all genes involved sulphur metabolism in C. glutamicum [15] in the intergenic region shared by $c$ g3118 and cg3119 (Fig. 1). 


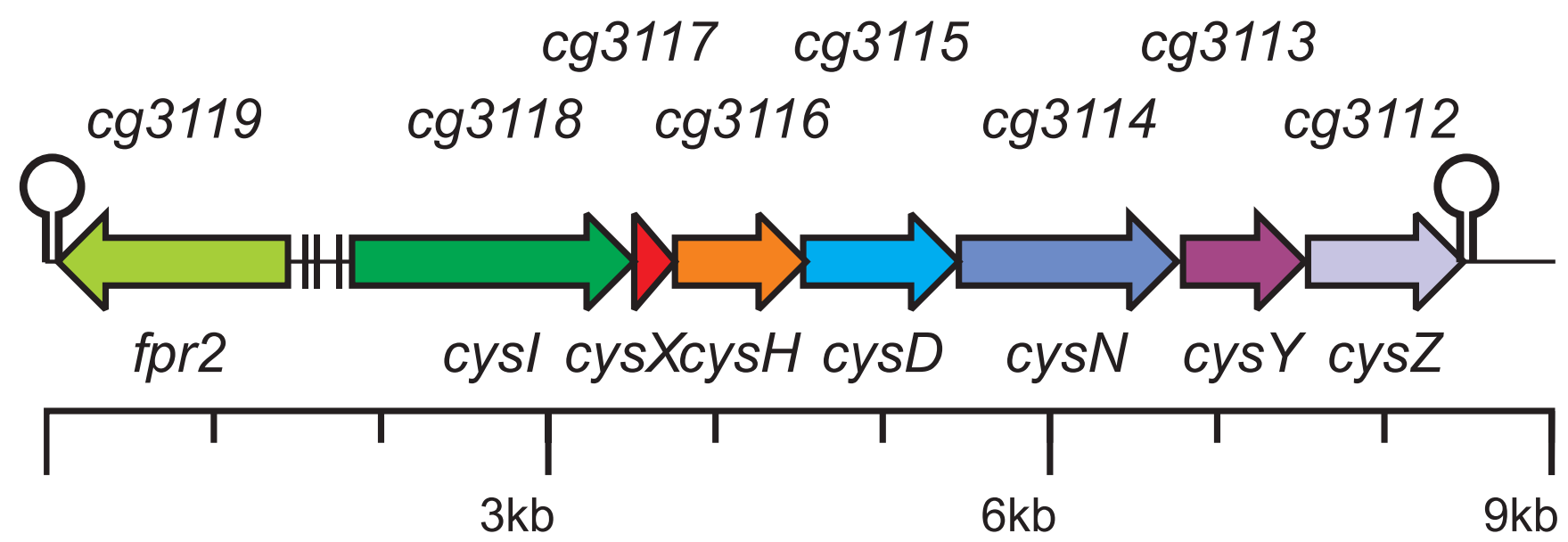

Figure I

The fpr2cysIXHDNYZ gene cluster in the $C$. glutamicum genome. Coloured arrows indicate genes that are part of the cluster most probably involved in assimilatory sulphate reduction. Hairpins mark potential rho-independent transcription termination signals predicted by the TransTerm software. Black bars denote binding sites for the transcriptional repressor McbR [15].

\section{Bioinformatic analysis of the Corynebacterium glutamicum candidate genes possibly involved in assimilatory sulphate reduction}

As a first step in the analysis of the eight candidate genes similarity searches against the UniProt and PFAM databases were done. These searches led to a functional assignment for $c g 3114$ and $c g 3115$ as $c y s D$ and $c y s N$ respectively, most likely encoding the two subunits for sulphate adenylyltransferase known from, e.g., E. coli (Table 1).

For Cg3118 and Cg3116, the similarity searches indicated possible deviations from the enzymatic functions described for E. coli (Table 1): Cg3118 (CysI) from C. glutamicum, while moderately similar to CysI from E. coli, displays a higher degree of similarity to ferredoxindependent sulphite and nitrite reductases (NirA) known from other Actinomycetales and plants. In turn, based on a multiple alignment, these sequences cluster much more closely with the ferredoxin-dependent nitrite reductases from plants and cyanobacteria (e.g. Nir from Synechococcus sp.) than with CysI homologues of the $a$ - and $\gamma$-proteobacteria (data not shown). Likewise, Cg3116 (CysH) was found to be much more similar to CysH from M. tuberculosis which has been proven to act as APS reductase (EC 1.8.4.10) [2]. Furthermore, all the sequence motifs demonstrated to be necessary for the reduction of APS [16] are present in CysH from C. glutamicum (data not shown).

For the proteins encoded by the four novel CDS $\operatorname{cg} 3112$, cg3113, cg3117, and cg3119, no significant similarities to proteins known to be involved in sulphate reduction were detected, and only Cg3119 shows similarities to well characterised proteins (Table 1). The gene cg3112 encodes a protein similar to putative membrane proteins of the domain of unknown function family 81 (DUF81), which consists of integral membrane proteins. The notion that Cg3112 is located in the membrane is further corroborated by the TMHMM software which predicts the presence of six transmembrane helices. The possible presence of a signal peptide, detected by SignalP, indicates a Secdependent insertion into the membrane (data not shown). Cg3113 is weakly similar to sirohydrochlorin ferrochelatase from $B$. megaterium, indicating a possible involvement in the biosynthesis of the siroheme cofactor of sulphite reductase. The small CDS encoding Cg3117 shows similarities to small hypothetical proteins in several Actinomycetales. A multiple alignment of the significant hits revealed the presence of a conserved sequence

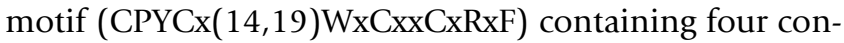
served cysteine residues. They are reminiscent of those found in Fe-S cluster coordination sites. Finally, Cg3119 is highly similar to FprA and FprB, known to act as ferredoxin-NADP reductases in mycobacteria. FprA from $M$. tuberculosis has been studied on the molecular level and is now classified as NADPH-ferredoxin reductase (EC 1.18.1.2), but it is unknown in which biological processes FprA and FprB are involved in $M$. tuberculosis $[17,18]$. Interestingly, a highly similar paralogue (Cg3049) is present in the C. glutamicum genome itself. Based on the well characterised FprA protein of M. tuberculosis, cg3049 and cg3119 were therefore named fprl and fpr2, respectively. 


\section{Comparison of the putative sulphate assimilation gene cluster of Corynebacterium glutamicum with gene clusters of other members of the actinomycetes}

As the cluster of genes possibly involved in sulphate assimilation had been found to be conserved between $C$. glutamicum and C. efficiens, the question arose whether the findings for sulphate assimilation in C. glutamicum are specific for these two organism or if the cluster and the pathway is conserved among the order of the Actinomycetales. Therefore, a search for conserved parts of the cluster in all completely sequenced genomes of the bacterial order as well as in the only partially completed genomes of Brevibacterium linens and Thermobifida fusca was conducted, using the programs GECKO [19] and TheSEED [20].

This approach revealed that most of the genes found to be involved in sulphur metabolism in C. glutamicum are also found in other members of the Actinomycetales. Notable exceptions are C. diphtheriae, Bifidobacterium longum, Leifsonia xyli, M. leprae, Propionibacterium acnes, and Tropheryma whipplei, as in all these organisms the genes needed for assimilatory sulphate reduction are completely absent All these organisms are known pathogens or commensals of humans, animals, or plants, the most likely explanation is that these bacteria obtain the required sulphurcontaining organic compounds directly from their hosts.

Concerning the conservation of the cluster, it was found to be almost perfectly conserved in C. glutamicum and $C$. efficiens (Fig. 2), as well as in the recently sequenced $C$. jeikeium [21]. In the other members of the Actinomycetales that contain the genes needed for sulphate assimilation, these genes are also clustered, but in many cases the cluster is split in two or three parts. In addition, duplications seem to have occurred, e.g., in M. avium, N. farcinica, and S. avermitilis.

Of the four novel genes cg3112,cg3113,cg3117 and cg3119 (fpr2), only a cg3113-like gene was found in all Actinomycetales containing parts of the cluster (Fig. 2), adding additional evidence that it is involved in sulphate assimilation. On the other hand, it proved to be the least conserved on the amino acid level (data not shown).

cg3112 seems to be present only in the Corynebacteriaceae. This might be due to the fact that in the Mycobacteriaceae, Streptomycetaceae, and N. farcinica an ABC-type transporter replaces $\mathrm{Cg} 3112$.

Fpr homologues are only found to be clustered with other cys genes in Corynebacteriaceae, but at least one possible homologue is present in all Actinomycetales that contain the cluster. Another hint for the involvement in the reduction of sulphate is the co-occurrence of Cg3117 and Fpr homologues lacking a ferredoxin-domain: M. tuberculosis, $M$. avium, and $N$. farcinica all contain a two-domain protein consisting of a ferredoxin-like and a Fpr-like domain. The Corynebacteriaceae, Streptomycetaceae, and T. fusca all lack such a protein but possess a Cg3117-homologue in the cluster. As the flavoprotein subunit of sulphite reductase CysJ is absent in all Actinomycetales, the data from the comparative genomics approach provides circumstantial evidence that the enzymatic equipment for sulphite reduction in the Actinomycetales is similar to that found in plants: In these eukaryotes electrons are transferred directly from photosystem I via ferredoxin-NADP reductase and ferredoxin to the ferredoxin-dependent sulphite reductase [22]. For C. glutamicum, this leads to the hypothesis that electrons might be transferred from $\mathrm{NADPH}+\mathrm{H}^{+}$ by Fpr2 to $\mathrm{Cg} 3117$ which in turn delivers them to the ferredoxin-dependent sulphite reductase.

\section{Characterisation of the Corynebacterium glutamicum gene cluster possibly involved in assimilatory sulphate reduction by targeted gene deletion, mutational analysis, and complementation}

To determine if the CDS of the identified gene cluster cg3119-3112 are involved in the assimilatory reduction of sulphate, deletion mutants of all genes were constructed. Gene-SOEing was used to create fusion products of chromosomal DNA sections of approximately 500 bp length directly up- and downstream of the target gene. The resulting fusion products were cloned into the vector pK18mobsacB and the obtained plasmids were used for targeted gene deletion.

The resulting mutants CR018 to CR025 (Table 4) were tested for their ability to grow on a solid minimal medium containing differing inorganic sulphur compounds at 2 $\mathrm{mM}$ concentration as sole source of sulphur. Seven of the eight mutant strains CR018 to CR024 were affected in their ability to utilise inorganic sulphur sources. The most common observed phenotype was a complete inability to grow, like strain CR024 $(\Delta c y s I)$ on medium containing sulphate or sulphite, but in some cases, growth was only severely reduced, like that of strain CR023 ( $\Delta c g 3117)$ when utilising oxidised inorganic sulphur compounds (Table 2).

All four mutants in the potential cys gene homologues (cg3114, cg3115, cg3116, and cg3118) were unable to utilise sulphate as sole source of sulphur while they could still grow on sulphide, thereby confirming that the encoded proteins are involved in the reduction of inorganic sulphur compounds. Surprisingly, the mutants lacking $c y s D, c y s H$, or $c y s N$ were also unable to grow on sulphite and displayed a reduced growth rate on thiosulphate. This observation stands in contrast to the findings 

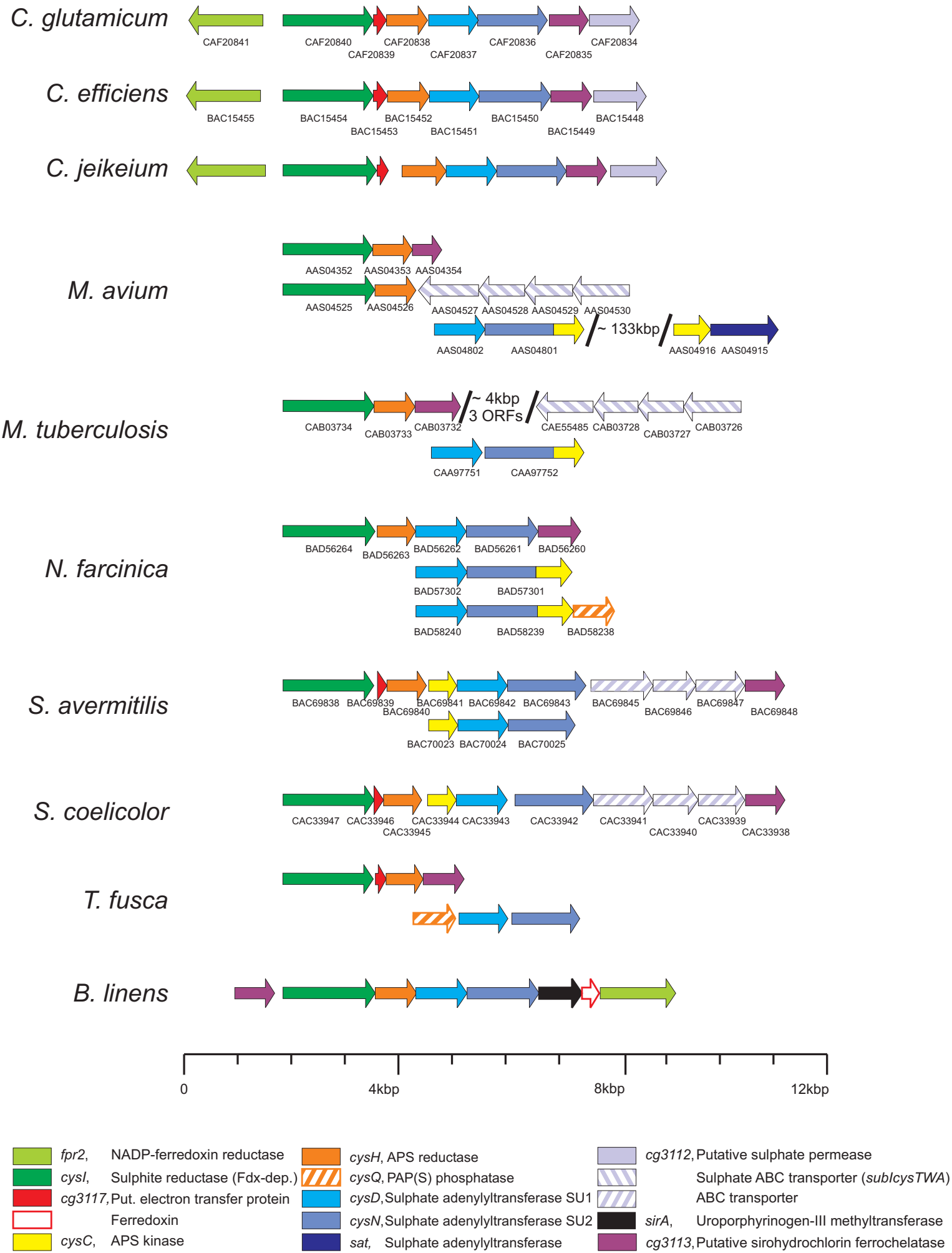

cg3112, Putative sulphate permease

Sulphate $\mathrm{ABC}$ transporter (sublcysTWA) $A B C$ transporter

sirA, Uroporphyrinogen-III methyltransferase

cg3113, Putative sirohydrochlorin ferrochelatase

Figure 2

Conservation of the $C$. glutamicum gene cluster possibly involved in assimilatory sulphate reduction in the Actinomycetales. Functions were inferred based on sequence similarity from BLAST searches against the UniProt database. Only those genes are displayed that were found to be clustered (at least two adjacent genes possibly involved in assimilatory sulphate reduction). 
Table 2: Growth of $C$. glutamicum mutant strains on different inorganic sulphur sources on solid minimal medium

\begin{tabular}{|c|c|c|c|c|c|c|}
\hline \multirow[b]{2}{*}{ strain } & \multirow{2}{*}{$\begin{array}{c}\text { deleted } \\
\text { CDS (gene) }\end{array}$} & \multicolumn{5}{|c|}{ growth ${ }^{a}$ after $48 \mathrm{~h}$ on MMS with addition of $2 \mathrm{mM}$ of } \\
\hline & & sulphate & sulphite & thiosulphate & sulphide & L-cysteine \\
\hline WT & l & + & + & + & + & + \\
\hline CROI8 & $\operatorname{cg} 3 / 12$ (cysZ) & - & - & + & + & + \\
\hline CRO19 & $\operatorname{cg} 31 / 3$ (cys $Y)$ & - & - & - & $\circ$ & + \\
\hline CR020 & $\operatorname{cg} 3 / 14(\operatorname{cys} N)$ & - & - & $\circ$ & + & + \\
\hline CR02I & $\operatorname{cg} 3115$ (cysD) & - & - & $\circ$ & + & + \\
\hline CR022 & $\mathrm{cg} 3 / 16(\mathrm{cys} H)$ & - & - & $\circ$ & + & + \\
\hline CR023 & $\operatorname{cg} 3117$ (cys $X)$ & $\circ$ & $\circ$ & $\circ$ & + & + \\
\hline CR024 & cg3/ I 8 (cysl) & - & - & - & $\circ$ & + \\
\hline CR025 & $\operatorname{cg} 3119(\mathrm{fpr} 2)$ & + & + & + & + & + \\
\hline
\end{tabular}

${ }^{a}$ compared to the wild-type grown on MMS containing sulphate:

+ denotes wild-type like growth

- indicates a severely reduced growth rate

- represents a complete lack of growth

made, e.g., for E. coli, where a loss of these genes does not influence the ability to utilise sulphite or thiosulphate [1].

Of the four novel genes, the mutational analysis provided strong evidence that the three previously uncharacterised CDS cg3117, cg3113, and cg3112 are involved in assimilatory sulphate reduction (Table 2). The corresponding mutant strains could either no longer grow on MMS containing only sulphate or sulphite $(\Delta c g 3113$ and $\Delta c g 3112)$ or displayed a severely reduced growth rate $(\Delta c g 3117)$. Therefore, they were named $c y s Y, c y s Z$, and $c y s X$, respectively. On the other hand, a loss of fpr2 did not influence growth under the tested condition, indicating that the encoded protein is either not involved in sulphate reduction or its function can be replaced, most likely by Fpr1, the product of $c$ g3049. Unfortunately, all attempts to verify this hypothesis failed, because deletion or disruption of fpr1 was not possible. This indicates that Fpr1 might have another, essential function in C. glutamicum.

As the genes cysI to cys $Z$ might constitute an operon, homologous complementation of the mutant strains CR018 to CR024 (Table 4) was used to verify that the observed phenotypes were due only to the loss of the deleted gene and not caused by polar effects on genes downstream of the deletion. This was done by PCR amplification of the gene in question and subsequent cloning of the product in a suitable expression vector. The resulting plasmids pCR018e to pCR024e (Table 4) were transferred into the corresponding mutant strains and the ability of the plasmid carrying strains to utilize inorganic sulphur sources was tested as described above. In all cases, growth of the mutant strain expressing the missing gene in trans was indistinguishable from that of the wild-type, thus ruling out polar effects.
The plasmids pCR020e, pCR022e and pCR024e (carrying $c y s D N, c y s H$, and $c y s I$, respectively) were also used to try heterologous complementation of corresponding E. coli mutant strains to get additional evidence for the assumed gene functions. Surprisingly, the complementation of $E$. coli JM221 (cysD-) and JM246 (cysi-) with pCR20e, respectively, failed. Only AB462 (cys $\left.\mathrm{C}^{-}\right)$and JM226 (cys $\left.\mathrm{H}^{-}\right)$carrying pCR022e were able to grow with sulphate as sole source of sulphur, and even these grew only slowly. These results add evidence to the hypothesis that $C$. glutamicum uses either a pathway differing from that in $E$. coli or that the enzymes can only function as a complex in $C$. glutamicum.

\section{Analysis of the Corynebacterium glutamicum gene cluster fpr2cysIXHDNYZ by growth tests in liquid culture} Based on the data obtained from the in silico and in vivo analysis, a hypothesis of the possible functional role of the four novel CDS was formulated, leading to a preliminary model for the pathway for assimilatory sulphate reduction in C. glutamicum: The presence of transmembrane domains and the inability of the mutant strain to grow on sulphate and sulphite as sole sources of sulphur indicated that CysZ might be involved in the uptake of these compounds. For CysY, a function in the biosynthesis of the siroheme cofactor of sulphite reductase could be supposed as the phenotype of the CR019 ( $\Delta c$ c3113) mutant strain was indistinguishable from that of CR024 ( $\Delta c y s I)$. The small protein CysX might be involved in electron transfer, with the four conserved cysteine residues possibly being part of a $\mathrm{Fe}-\mathrm{S}$ cluster like those found in ferredoxins. For Fpr2, a function in the reduction of ferredoxins could be assumed, possibly acting on CysX. 
In order to substantiate these hypotheses, growth of the mutant strains CR018, CR019, CR023, and CR025 ( $\Delta c$ cysZ, $\Delta c y s Y, \Delta c y s X$, and $\Delta f p r 2$, respectively) was measured via real-time nephelometry in liquid minimal medium on different inorganic sulphur sources at a concentration of 2 $\mathrm{mM}$. From the obtained growth curves, the generation times and the duration of the lag phases were calculated and compared to those determined for the wild-type strain (Table 3).

This approach confirmed the observations made during growth on solid minimal medium. In the case of CysX, it provided further evidence for the hypothesis that CysX might act like a ferredoxin: The generation time of the mutant strain CR023 $(\Delta c y s X)$ is doubled to tripled (Table 3 ), indicating that the function of CysX can be partially replaced by another protein, most likely one of the ferredoxins found in C. glutamicum. Interestingly, under these conditions strain CR025 ( $\Delta f p r 2)$ also delivered a phenotype, namely an increase in the lag phase during growth with sulphate or sulphite of approximately three hours. This provides circumstantial evidence that Fpr2 is indeed involved in sulphur reduction, although its loss can be compensated for.

As prior growth tests on solid minimal medium containing high concentrations of sulphate had shown that strain CR018 ( $\Delta c y s Z$ ) could grow under these conditions (data not shown), additional tests with this strain were performed in liquid culture using varying concentrations of sulphate. These tests confirmed that the mutant strain is unable to grow with sulphate concentrations of less than $5 \mathrm{mM}$. With increasing sulphate concentration, growth is gradually restored until, at above $30 \mathrm{mM}$, it reaches almost the level of the wild-type strain (Fig. 3). This concentration-dependent restoration of growth provides strong evidence that CysZ acts as the high-affinity sulphate transporter in C. glutamicum. Furthermore it indicates that at least one other transporter for sulphate must exist which is able to function effectively only at sulphate concentrations above $5 \mathrm{mM}$.

\section{Transcriptional analysis of the Corynebacterium glutamicum cys gene cluster}

As gene order and the presence of possible transcription termination sites indicated that the genes cysI to cys $Z$ might form an operon (Fig. 1), real-time RT-PCR was used to verify this hypothesis. To disrupt the hypothetical operon, a transposon mutant in cysI (CR026, insertion 997 bp downstream of the cysI gene start) was used, as it could be assumed that the insertion of the transposon and the vector with a size of $\approx 5.5 \mathrm{~kb}$ would lead to a premature termination of transcription. Using real-time RT-PCR, the mRNA levels of the seven genes in the wild-type and the mutant strain both grown with L-cysteine as sulphur source were compared. The measurements revealed an equally strong reduction of the relative mRNA levels of all seven genes in the mutant downstream of the transposon insertion site (Fig. 4). This observation and the finding that the mRNA level upstream of the insertion is only slightly increased provides strong evidence that $c y s I X H D$ NYZ indeed form an operon and that no additional promoters downstream of $c y s I$ exist.

Real-time RT-PCR was also applied to analyse whether the clustered genes are subject to regulation by either one or more of the inorganic substrates or by the products of assimilatory sulphur reduction (namely sulphide and Lcysteine). Therefore, the mRNA levels of fpr2, cysI, and cys $Z$ in cells incubated in MMS with different sulphur sources at $1 \mathrm{mM}$ concentration was compared with those in cells incubated in MMS without added sulphur. In all cases with the exception of thiosulphate, a strong simultaneous reduction of mRNA abundance of all three genes in cells incubated with a sulphur source was observed (Fig. $5 \mathrm{~A})$. Transcription levels of the genes of the cluster were found to be strongly reduced in the presence of most inorganic sulphur sources while L-cysteine had a much weaker, albeit still significant effect. Surprisingly, the relative transcription levels decreased only marginally in presence of thiosulphate, even at higher concentrations of up to $5 \mathrm{mM}$ (data not shown).

Table 3: Growth characteristics of $C$. glutamicum mutant strains on different inorganic sulphur sources at 2 mM concentration in liquid medium

\begin{tabular}{|c|c|c|c|c|c|c|c|c|c|c|}
\hline \multirow[b]{2}{*}{$\begin{array}{l}\text { sulphur } \\
\text { source }\end{array}$} & \multicolumn{5}{|c|}{ generation time ${ }^{a}[\mathrm{~h}]$} & \multicolumn{5}{|c|}{ lag time ${ }^{a}[\mathrm{~h}]$} \\
\hline & WT & $\begin{array}{l}\text { CR0I8 } \\
(\Delta \text { cysZ) }\end{array}$ & $\begin{array}{l}\text { CRO19 } \\
(\Delta \text { cys } Y)\end{array}$ & $\begin{array}{l}\text { CR023 } \\
(\Delta \text { cys } X)\end{array}$ & $\begin{array}{l}\text { CR025 } \\
(\Delta f p r 2)\end{array}$ & WT & $\begin{array}{l}\text { CROI8 } \\
(\Delta \text { cysZ) }\end{array}$ & $\begin{array}{l}\text { CROI9 } \\
(\Delta \text { cys } Y)\end{array}$ & $\begin{array}{l}\text { CR023 } \\
(\Delta \text { cys X) }\end{array}$ & $\begin{array}{l}\text { CR025 } \\
(\Delta f p r 2)\end{array}$ \\
\hline sulphate & 2.1 & $\mathbf{n d}^{b, c}$ & nd & 6.2 & 2.2 & 8.0 & nd & nd & 23.5 & 11.0 \\
\hline sulphite & 2.2 & nd & nd & 4.2 & 2.1 & 8.0 & nd & nd & 16.0 & 11.0 \\
\hline $\begin{array}{l}\text { thiosulphat } \\
\mathrm{e}\end{array}$ & 3.2 & 3.2 & nd & 9.5 & 2.9 & 9.5 & 14.0 & nd & 37.5 & 10.5 \\
\hline sulphide & 3.8 & 3.8 & 17.6 & 7.4 & 3.2 & 15.0 & 13.5 & 16.5 & 23.5 & 15.5 \\
\hline
\end{tabular}

${ }^{a}$ averages, calculated from 18 measurements ( 3 independent cultivations, 6 replicates per cultivation)

$b$ significant changes are given in bold script

$c_{\text {nd }}=$ not determined due to lack of growth 
Table 4: Bacterial strains and plasmids

\begin{tabular}{|c|c|c|}
\hline Name & Relevant genotype/information ${ }^{a}$ & Source/reference \\
\hline \multicolumn{3}{|l|}{ E. coli } \\
\hline DH5 $\alpha$ MCR & 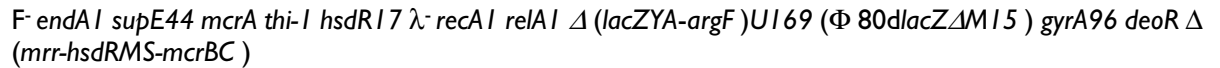 & {$[40]$} \\
\hline AB462, CGSC 462 & F-DE (gpt-proA )64 lacYl galK2 (Oc)hisG4 (Oc) $\lambda$ - cysC9 xylA5 mtl-I thi-I & CGSCb \\
\hline JM226, CGSC 5468 & F- pro-0 lac -tsx -? galT47 trp-74 his -cysH57 xyl argA9999 rpsL -(strR) mal -ilvA -mtl - & CGSC, [47] \\
\hline JM22I, CGSC 5745 & F- pro-50 lac- tsx -galT47 trp-74 his-97 cysD9I argA-rpsL--(strR) mat xyl-ilvA-mtl- & CGSC, [47] \\
\hline JM246, CGSC 5747 & $\mathrm{~F}-\lambda-\operatorname{cys} I 53(\mathrm{Am}) / \mathrm{N}(\mathrm{rrnD}-\mathrm{rrnE}) / \mathrm{rph}-\mathrm{I}$ & CGSC, [47] \\
\hline \multicolumn{3}{|l|}{ C. glutamicum } \\
\hline ATCC 13032 & Wild type, $\mathrm{Nx}^{\mathrm{r}}$ & ATCC \\
\hline CROI8 & $\Delta \operatorname{cg} 3 / 12$ (cysZ) & this study \\
\hline CROI9 & $\Delta \operatorname{cg} 31 / 3($ cys $Y)$ & this study \\
\hline CR020 & $\Delta \operatorname{cg} 3 / / 4(\operatorname{cys} N)$ & this study \\
\hline CR02I & $\Delta c g 3 / 15(c y s D)$ & this study \\
\hline CR022 & $\Delta \operatorname{cg} 3 / 16(c y s H)$ & this study \\
\hline CR023 & $\Delta \operatorname{cg} 3 / 17(\operatorname{cys} X)$ & this study \\
\hline CR024 & $\Delta \operatorname{cg} 3 / 18($ cysl) & this study \\
\hline CR025 & $\Delta \mathrm{cg} 31 / 9(\mathrm{fpr} 2)$ & this study \\
\hline CR026 & $\operatorname{cg} 31 / 8:: 1 S 6100$, pAT6100 & this study \\
\hline \multicolumn{3}{|l|}{ Plasmids } \\
\hline pKI8mobsacB & $\begin{array}{l}\text { sacB, lacZa, } \mathrm{Km}^{\mathrm{r}} \text {, mcs mobilizable vector, allows for selection of double-crossover in C. glutamicum } \\
\text { mobilizable vector, allows for selection of double-crossover in C. glutamicum }\end{array}$ & {$[35]$} \\
\hline pEC-XK99E & Ptrc, laclq, $\mathrm{Km}^{r}$ inducible $E$. coli - C. glutamicum - shuttle expression vector & [48] \\
\hline PAT6100 & $\mathrm{IS6} 6 \mathrm{I} 00, \mathrm{Km}^{\mathrm{r}}$ & [36] \\
\hline PCROI8d & pK 18 mobsacB carrying cg3 $/ 12$ deld & this study \\
\hline $\mathrm{pCRO} / 8 \mathrm{e}$ & pEC-XK99E carrying cysZ eve & this study \\
\hline PCROI9d & pK 18 mobsacB carrying cg $3 / 13$ del & this study \\
\hline $\mathrm{PCRO} / 9 \mathrm{e}$ & pEC-XK99E carrying cys $Y$ ev & this study \\
\hline pCR020d & pK I8mobsacB carrying cg3//4 del & this study \\
\hline $\mathrm{pCR020e}$ & pEC-XK99E carrying cysDN ev & this study \\
\hline pCR02Id & pK 18 mobsacB carrying cg $3 / 15$ del & this study \\
\hline PCR022d & pK 18 mobsacB carrying cg $3 / 16$ del & this study \\
\hline $\mathrm{PCR} 022 \mathrm{e}$ & pEC-XK99E carrying cys H ev & this study \\
\hline PCR023d & pK I8mobsacB carrying cg3/I7 del & this study \\
\hline PCR023e & pEC-XK99E carrying cys X ev & this study \\
\hline pCR024d & pK 18 mobsacB carrying cg $31 / 8$ del & this study \\
\hline $\mathrm{pCR024e}$ & pEC-XK99E carrying cysl ev & this study \\
\hline PCR025d & pK 18 mobsacB carrying cg3/19 del & this study \\
\hline
\end{tabular}

${ }^{a} \mathrm{r}$ superscript indicates resistance. $\mathrm{nx}$, Nalidixic acid; $\mathrm{Km}$, Kanamycin

b CGSC; E. coli Genetic Stock Center, Yale University, New Haven, CT

cATCC; American Type Culture Collection, Rockville, MD

$d$ the postfix del indicates inserts used for targeted gene deletion

e the postfix ev indicates genes preceded by an artificial RBS

This data clearly proves that the assimilation of sulphur in C. glutamicum is regulated by either the substrates or the products of the assimilatory reduction of sulphate. Furthermore, the data indicates that this regulation is different from that found in E. coli, as thiosulphate has been shown to repress transcription of the cys genes in that organism [1]. Finally, the co-regulation of fpr2 and the cys genes in C. glutamicum also provides circumstantial evidence that Fpr2 is involved in the reduction of sulphate.
The strong regulation of the three genes under study raised the question at which concentration it would occur. Therefore, the relative transcription levels in the presence of varying amounts of sulphate were measured. By this approach it could be demonstrated that already at a concentration of $100 \mu \mathrm{M}$ sulphate the genes are as strongly repressed as in the presence of $1 \mathrm{mM}$ sulphate and more while at $50 \mu \mathrm{M}$ sulphate transcription levels are comparable to those observed in MMS without added sulphur (Fig. 5B). 


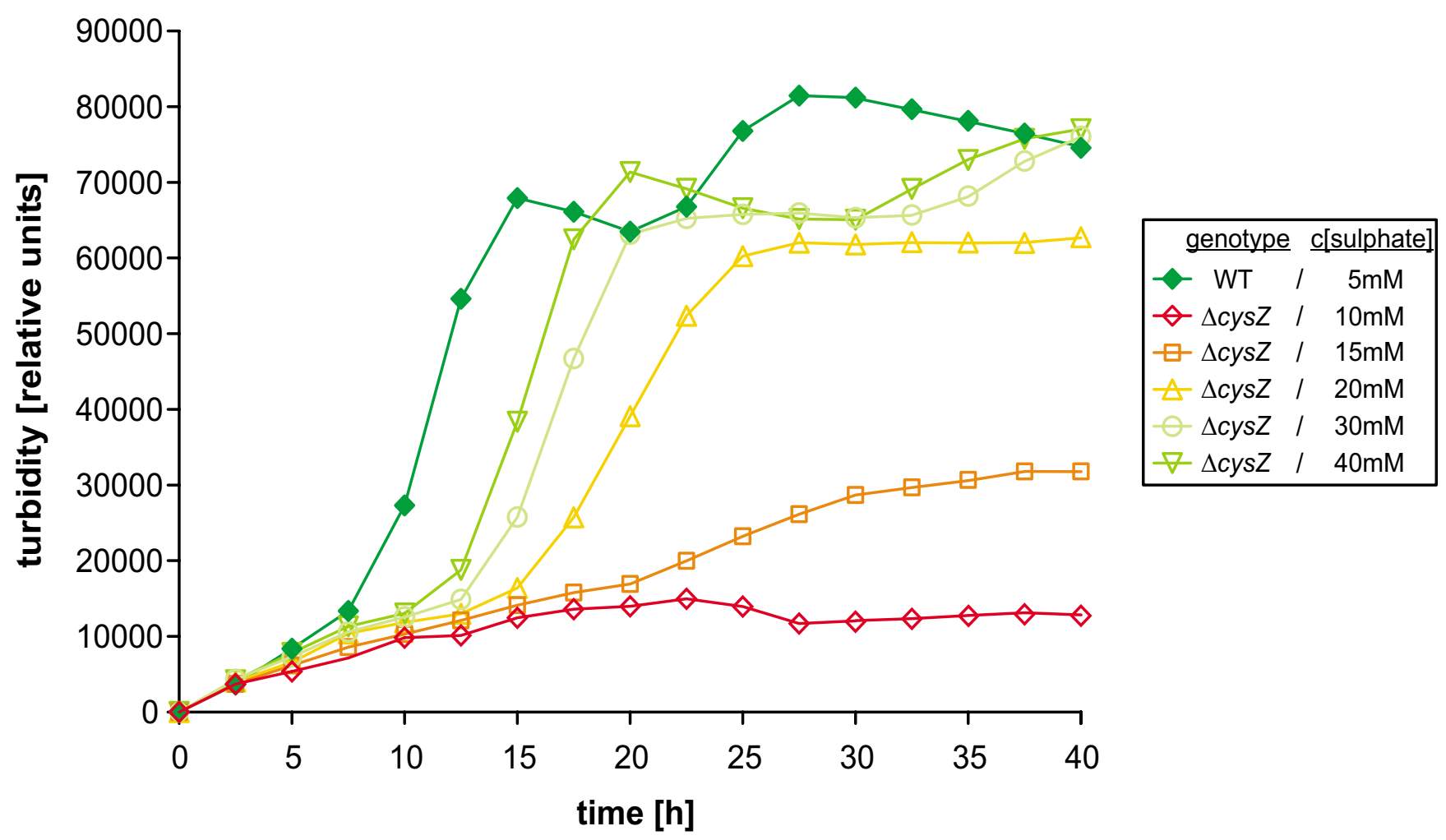

Figure 3

Growth of the $C$. glutamicum wild-type and the $\Delta c y s Z$ mutant strain in medium with different sulphate concentrations. Wild-type and mutant strain were grown in liquid minimal medium, cell growth was determined by real-time nephelometry. For each time point the mean of 18 measurements is displayed ( 3 independent cultivations, 6 parallels per cultivation). The wild-type strain is denoted with filled diamonds, open symbols are used to indicate the mutant strain.

\section{Determination of the transcription start sites in front of} the Corynebacterium glutamicum fpr 2 and cysl genes As the real-time RT-PCR data indicated that all seven $c y s$ genes are described from one promoter, the RACE technique was applied to identify the promoter elements in the intergenic region between fpr 2 and cysI. Thereby, one transcription start point was identified for each of the two transcription units (Fig. 6). The sequences upstream were compared to the the $\sigma^{70}$ consensus promoter [23] revealing two hexamers showing similarity to the -10 and -35 region including an optimal spacing of 17 bases, but no elements of an extended -10 region are detectable (Fig. 6). These hexamers are in 7 respectively 8 of 12 positions identical to the consensus sequence, which represents an average value for promoters in C. glutamicum, with the most conserved bases of the consensus promoter also present in the two promoters described here. An interesting finding was the observation that both promoters overlap with potential binding-sites of the transcriptional repressor McbR [15]. This strongly indicates that McbR is involved in the observed regulation.

\section{Discussion}

In this report, we describe the identification and validation of a set of genes involved in the assimilatory reduction of sulphate in Corynebacterium glutamicum, including the up to now unknown genes $c y s X, c y s Y, c y s Z$, and $f p r 2$.

Initial comparison of the genetic equipment for the assimilatory reduction of sulphate indicated that C. glutamicum possesses a set of genes similar to that known from $E$. coli [1], with exception of $c y s C$ (encoding APS kinase) and $c y s J$ (encoding the flavoprotein subunit of sulphite reductase). On the other hand, genes typical for B. subtilis like sat [3], $y \ln F[7]$, and $c y s P[3]$ could not be found in C. glutamicum. Despite several similarities, the pathway present in $C$. glutamicum displays several features that distinguish it from that described for $E$. coli, based on the obtained data (Fig. 7):

Uptake of sulphate is most likely mediated by a novel type of permease, CysZ, instead of the ABC-type transporter Sbp CysPTWA known from E. coli $[24,25]$. Although not 


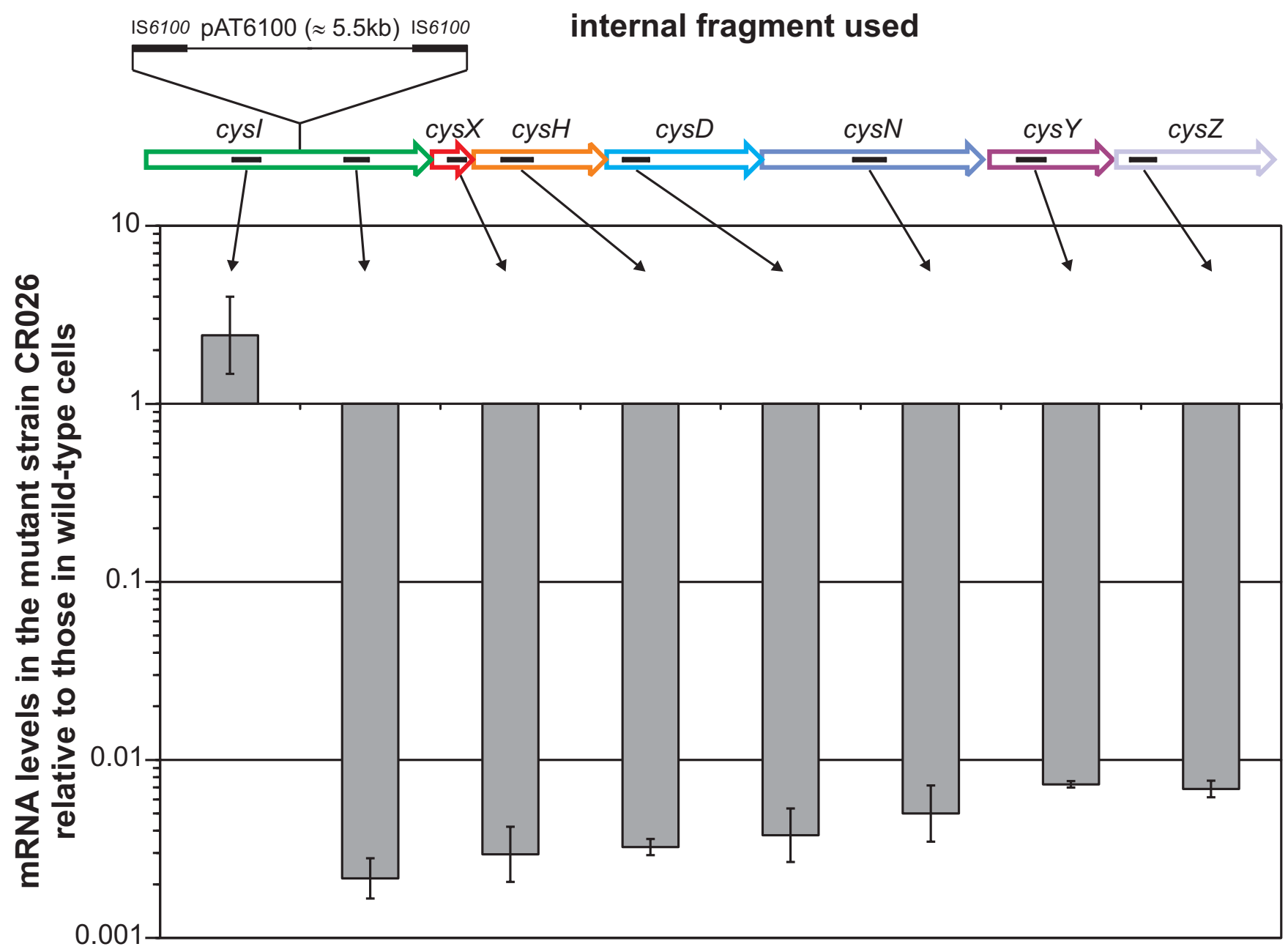

\section{Figure 4}

Comparison of the mRNA levels of the cys genes of the $C$. glutamicum wild-type and a cysl transposon mutant. Total RNA was isolated from cells grown in MMS with I mM L-cysteine as sulphur source and the relative transcription levels were determined using real-time RT-PCR to quantify the mRNAs of the displayed genes. Small black bars inside the arrows representing the genes indicate the position of the internal fragments amplified in the real-time RT-PCR.

proven by biochemical data, the observed growth deficits of the $\Delta c y s Z$ mutant strain together with the bioinformatic evidence that CysZ is located in the membrane strongly support this theory. Interestingly, the obtained data also indicates the existence of at least one low-affinity sulphate transporter and one or more transporter(s) for the uptake of the other inorganic sulphur compounds (like thiosulphate) which are not clustered with the other $c y s$ genes in C. glutamicum.

Strong evidence also exists that the activation of sulphate and the subsequent reduction to sulphite is performed in only two steps in C. glutamicum: Like cys $H$ from $M$. tuberculosis [2], the heterologous expression of $c y s H$ from
C. glutamicum can complement E. coli $c y s H^{-}$as well as $c y s C^{-}$ mutants. This and the missing of a homologue of APS kinase clearly indicate that CysH acts as APS reductase in C. glutamicum, corroborating the prediction made by Lee [26].

The final step, the reduction of sulphite to sulphide seems to differ the most from the situation found in E. coli and B. subtilis, albeit this hypothesis is backed only by circumstantial evidence: CysI from C. glutamicum and the potential homologues in the other Actinomycetales share the highest degree of similarity to ferredoxin-dependent nitrite and sulphite reductases found in plants and cyanobacteria. Together with the presence of Fpr and 
A)

internal fragment used

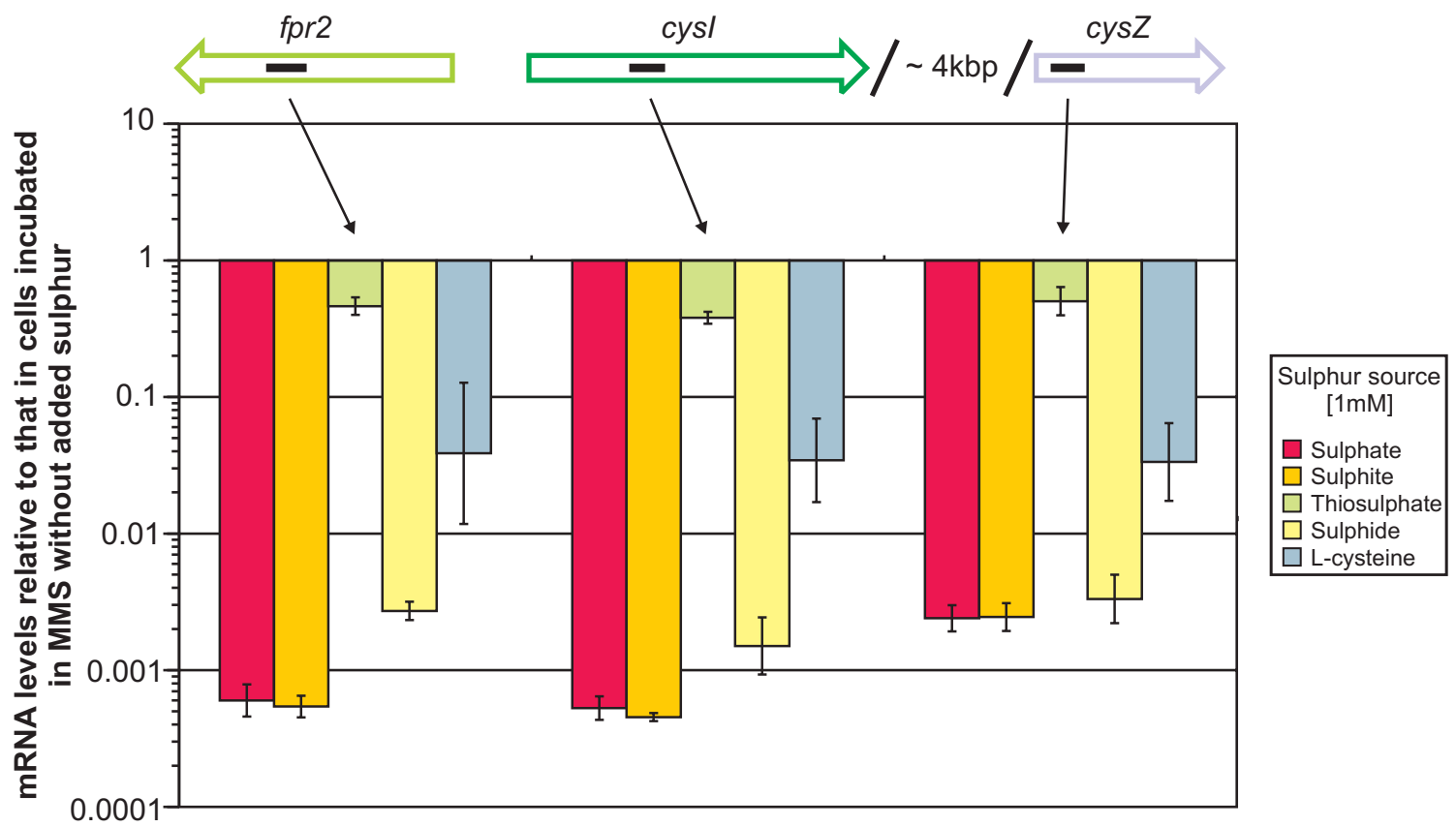

B)

internal fragment used

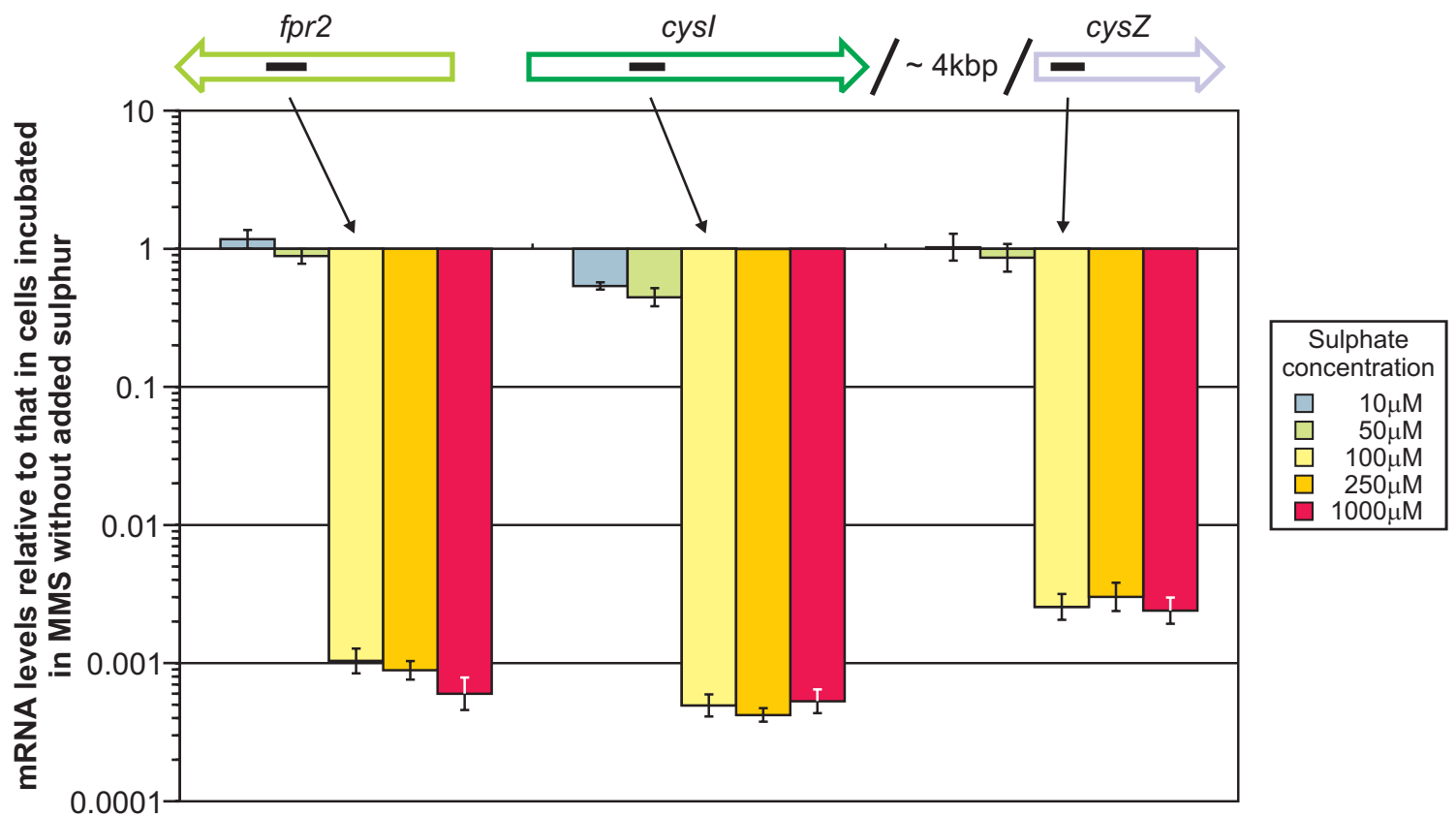

Figure 5

Change of the fpr2cysIXHDNYZ mRNA levels in the presence of different sulphur sources and varying amounts of sulphate. The relative mRNA levels of the $\mathrm{fpr} 2$, cysl, and cysZ genes in cells incubated in MMS with either (A) different sulphur sources at I mM concentration or (B) sulphate at varying concentrations were compared to that in cells incubated in MMS without additional S-sources using real-time RT-PCR. Small black bars inside the arrows representing the genes indicate the position of the internal fragments used in real-time RT-PCR. 


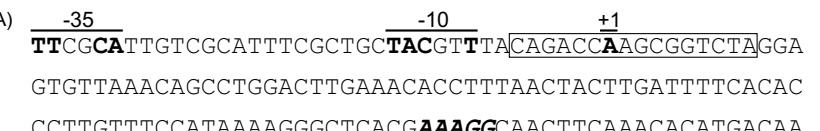
CCTTGTTTCCATAAAAGGGCTCACGAAAGGCAACTTCAAACACATGACAA

B)

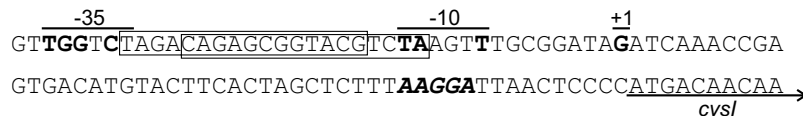

Figure 6

The promoter/operator regions of the $C$. glutamicum fpr2 and cysl genes. The determined transcriptional start points of the two transcriptional units fpr2 (A) and cysIXHD$N Y Z(B)$ are marked as ' $+I$ '. Parts of the two potential promoters $(-35,-10,+1)$ are overlined, bases in bold type in these regions indicate bases matching the $C$. glutamicum $\sigma^{70}$ consensus promoter [23]. DNA motifs matching the consensus sequence of the McbR binding-site are boxed. Bases in bold italics mark potential ribosome binding-sites, open underlining arrows indicate the annotated starts of genes.

CysX, this leads to the hypothesis that electrons are transferred from $\mathrm{NADPH}+\mathrm{H}^{+}$via Fpr2 and CysX to CysI to reduce sulphite, similar to the pathway used in non-photosynthetic plant tissues [22]. Unfortunately, this hypothesis could not be proven conclusively with the used genetic methods alone. The loss of CysX clearly affected growth on all oxidised inorganic sulphur compounds, but the exact function cannot be inferred from this analysis. In case of Fpr2, the phenotypical evidence is even weaker as a mutant lacking Fpr2 is almost unaffected in the utilisation of sulphate and sulphite, except for a slightly increased lag phase. Still, the absence of a clear phenotype is easily explainable by the presence of a highly similar paralogous protein, Fpr1, that seems to be essential. The notion that Fpr2 is indeed involved in the pathway under study is also supported by the finding that it is co-regulated with the genes of the cys operon and is controlled by McbR, the global regulator of sulphur metabolism in $C$. glutamicum [15].

Based on the phenotype of the deletion mutant, CysY is also involved in the reduction of sulphite. The weak similarity of CysY to sirohydrochlorin ferrochelatase from $B$. megaterium (EC 4.99.1.4) [27] indicates an involvement in the biosynthesis of the siroheme cofactor of sulphite reductase, but again this assumption cannot be proven conclusively by genetic analysis alone.

Concerning the pathway as a whole, the data from the mutational analysis, i.e. the inability of $c y s H, c y s D$, and $c \gamma s \mathrm{~N}$ mutants to utilise sulphite, and the failed heterologous complementation of E. coli cys mutants, suggest that

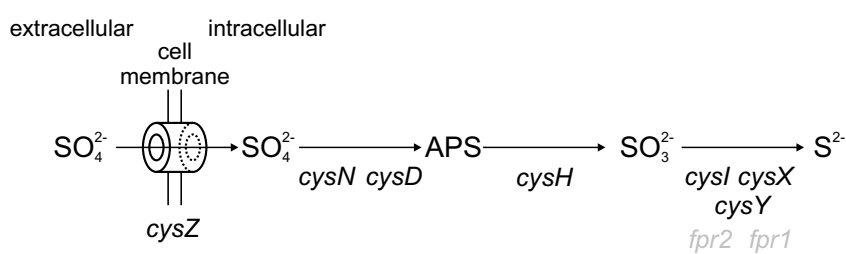

\section{Figure 7}

Model of the pathway for assimilatory sulphur reduction in C. glutamicum.. For proteins with gene names given in black, the involvement in the reduction of sulphate has been verified experimentally, for those in grey it has been inferred from circumstantial evidence.

the enzymes might form a multi-enzyme complex in $C$. glutamicum.

By analysing the mRNA levels of the eight clustered genes, it could be proven that $c y s I X H D N Y Z$ constitute one single transcription unit. This unit seems to be co-regulated with $f p r 2$, as expression of both was found to be strongly influenced to the same extent by the presence of most inorganic sulphur sources and L-cysteine.

The observed reduction of the mRNA levels of the eight genes under study in presence of various sulphur sources is reminiscent of the regulation described for E. coli [1] with exception for thiosulphate which also causes a strong anti-induction in E. coli. For C. glutamicum, it remains to be determined if the observed regulation is an anti-activation, as in E. coli, or a repression of a sulphur-starvation response. Based on the gathered data, the latter appears to be more likely, as $c y s I$ has been shown to be regulated by McbR, the global repressor of sulphur metabolism [28]. Mapping of the potential promoters of $c y s I$ and fpr2 revealed that both overlap with potential binding-sites of this master regulator [15], which corroborates the finding of Rey et al. that the transcription of the genes of the cluster is increased in a $\Delta m c b R$ mutant [15]. This strongly suggests that the observed regulation is at least in part due to the action of McbR. This hypothesis is further backed by the finding that McbR was found to be conserved in all completely sequenced Corynebacteriaceae [29] which is in accordance with the high degree of conservation of the cluster in C. glutamicum, C. efficiens, and C. jeikeium. Other candidates that might be involved in the regulation of the cluster are two genes under McbR-control, cg0012 and cg0156. The corresponding proteins both belong to the ROK/NagC-type family of regulators [29] and cg0012 has recently been proven to be involved in the metabolism of sulphur as it encodes the sulphate-inhibited activator of sulphonate utilisation, SsuR [30]. Therefore, cg0156 is a 
interesting candidate encoding a possible regulatory protein that should be characterised in a future study.

Although the regulatory protein(s) involved are not yet known, the regulatory network has been demonstrated to act extremely sensitive, as an external sulphate concentration of only $100 \mu \mathrm{M}$ already leads to a strong reduction of the mRNA levels of the fpr2 and cys genes by almost 1000fold. This might indicate that the cell needs to strictly control the amounts of reduced sulphur, which is plausible as most of these compounds are toxic.

An interesting finding was the high degree of conservation among cys gene clusters in different members of the Actinomycetales. With exception of several pathogens and commensals. As the pathway described for C. glutamicum in this study seems to be present, with slight deviations, in at least 11 other species, it stands to argue that the findings for one member of this order can be easily transferred to other members. As C. glutamicum is one of the few nonpathogenic species of the Actinomycetales, and the genes, with exception of $f p r$, are present in only one copy, this bacterium is well suited to study this important pathway more closely, e.g. on the biochemical level.

\section{Conclusion}

Based on sequence similarity, comparative genomics, and subsequent mutational analysis, we were able to identify a cluster of eight genes involved in assimilatory sulphate reduction. The obtained data supports a conclusive model for this pathway in C. glutamicum which differs considerably from those described for E. coli and B. subtilis, although further biochemical studies are necessary to prove the suggested functions. By using comparative genomics, we could gather strong evidence that the pathway described here might be present in at least 11 other members of the actinomycetes, thus distinguishing this group from the Gram-negative and low-GC Gram-positive bacteria in this metabolic function.

Furthermore, we could demonstrate that the eight genes under study are strongly regulated by the presence of either substrates and products of this pathway. Although reminiscent of the regulation described for E. coli, mapping of the transcription start points revealed that the $C$. glutamicum gene cluster might be controlled by repression of transcription rather than by anti-activation.

\section{Methods}

\section{Bacterial strains, plasmids and culture media}

The bacterial strains and plasmids used in this study are listed in Table 4. E. coli strains carrying plasmids were routinely grown on solid Antibiotic Medium No. 3 (PA) (Oxoid, Wesel, Germany) at $37^{\circ} \mathrm{C}$. C. glutamicum strains were grown on solid brain-heart broth (BH) (VWR Inter- national, Darmstadt, Germany) at $30^{\circ} \mathrm{C}$. Auxanography on solid medium was performed using a minimal medium (MMS), containing only trace amounts of inorganic sulphur. MMS is composed of $5 \%$ glucose, 150 $\mathrm{mM} \mathrm{NH}_{4} \mathrm{Cl}, 50 \mathrm{mM}$ urea, $6 \mathrm{mM} \mathrm{K}_{2} \mathrm{HPO}_{4}, 1.5 \mathrm{mM} \mathrm{MgCl}_{2}$, $70 \mu \mathrm{M} \mathrm{FeCl}_{2}, 50 \mu \mathrm{M} \mathrm{MnCl}_{2}, 70 \mu \mathrm{M} \mathrm{CaCl}_{2}, 7.5 \mu \mathrm{M} \mathrm{ZnCl}_{2}$, $1 \mu \mathrm{M} \mathrm{CuCl}_{2}, 0.1 \mu \mathrm{M}, \mathrm{NiCl}_{2}, 500 \mu \mathrm{g} / \mathrm{l}$ thiamine, and $50 \mu \mathrm{g} /$ 1 biotin, for the growth test different sulphur sources were added at $2 \mathrm{mM}$ concentration (calculated for sulphur). For solidification, $16 \mathrm{~g}$ agarose were added per litre MMS.

For growth tests in liquid medium, a modified version of MME [31], called MMES, was used, consisting of 2.5\% glucose, $17 \mathrm{mM} \mathrm{NaNH}{ }_{4} \mathrm{HPO}_{4}, 1 \mathrm{mM} \mathrm{MgCl}, 60 \mathrm{mM}$ $\mathrm{K}_{2} \mathrm{HPO}_{4}, 10 \mathrm{mM}$ citric acid, $37.5 \mu \mathrm{M} \mathrm{FeCl}_{2}, 50 \mu \mathrm{M} \mathrm{MnCl}_{2}$, $67.5 \mu \mathrm{M} \mathrm{CaCl}_{2}, 7.5 \mu \mathrm{M} \mathrm{ZnCl}, 1 \mu \mathrm{M} \mathrm{CuCl}_{2}, 0.1 \mu \mathrm{M}$, $\mathrm{NiCl}_{2}, 500 \mu \mathrm{g} / \mathrm{l}$ thiamine, and $50 \mu \mathrm{g} / \mathrm{l}$ biotin, with addition of different sulphur sources at varying concentrations.

Sulphur sources used were sodium sulphate $\left(\mathrm{Na}_{2} \mathrm{SO}_{4}\right)$, sodium sulphite $\left(\mathrm{Na}_{2} \mathrm{SO}_{3}\right)$, sodium thiosulphate $\left(\mathrm{Na}_{2} \mathrm{~S}_{2} \mathrm{O}_{3}\right)$, sodium sulphide $\left(\mathrm{Na}_{2} \mathrm{~S}\right)$, and L-cysteine.

Antibiotics used for selection of plasmids and strains were nalidixic acid ( $50 \mu \mathrm{g} / \mathrm{ml}$ for corynebacteria) and kanamycin (50 $\mu \mathrm{g} / \mathrm{ml}$ for E. coli, $25 \mu \mathrm{g} / \mathrm{ml}$ for corynebacteria).

\section{DNA isolation, transfer and manipulation}

Standard procedures were employed for molecular cloning and transformation of E. coli DH5 $\alpha$, as well as for electrophoresis [32]. Transformation of C. glutamicum was performed by electroporation using the methods of Tauch et al. [33].

\section{Construction of plasmids}

Plasmids pCR016d to pCR025d were constructed using the gene splicing by overlap extension (gene-SOEing) method described by Horton et al. [34], the PCR primers used are listed in the supplementary Table S1 [see Additional file 1]. The primary products were amplified using Pwo DNA polymerase (Roche, Mannheim, Germany). The resulting products were purified using the PCR purification kit (QIAGEN, Hilden, Germany) and used as templates for the second round of PCR. The final products were digested with restriction enzymes corresponding to the cleavage sites introduced via PCR and ligated into appropriately digested $\mathrm{pK} 18 \mathrm{mobsacB}$. The ligation mixture was used to transform E. coli DH5 $\alpha \mathrm{MCR}$, the transformants were selected on PA plates containing $50 \mu \mathrm{g} / \mathrm{ml} \mathrm{kan-}$ amycin and $40 \mathrm{mg} / \mathrm{l} \mathrm{X-Gal} \mathrm{(5-bromo-4-chloro-3-indolyl-}$ $\beta$-D-galactopyranoside).

Plasmids for complementation experiments were created by amplifying the gene of interest via PCR. The resulting 
constructs were cleaved using restriction sites added by the PCR primers and then ligated into plasmid pZ8-1, cut with the corresponding enzymes. The ligation mixture was used for transformation of E. coli DH5 $\alpha M C R$, the transformants were selected on PA plates containing 50 $\mu \mathrm{g} / \mathrm{ml}$ kanamycin.

\section{Site-specific gene deletion}

Site-specific gene deletion was performed using the nonreplicable integration vector $\mathrm{pK} 18$ mobsacB which allows for marker-free deletion of the target gene [35]. The plasmids pCR018d to pCR025d were transferred into the $C$. glutamicum wild-type strain (ATCC 13032) by electroporation [33]. Tests for first and second cross-over were performed as described previously [8].

\section{Identification of a cysl transposon mutant}

Using a cloned copy of the IS6100 mobile element [36], a transposon mutant library was constructed. The mutants were gained with a modified approach that uses electrotransfer of the IS6100-based transposon vector pAT6100 into the C. glutamicum host cells. Subsequent phenotypic screening of the transposon library for cystein-auxotrophic mutants was applied, and the transposon integration loci of these mutants were determined by a plasmid rescue technique and subsequent sequence similarity analysis [37].

\section{Relative quantification of $m R N A$ levels using real-time $R T$ - PCR}

Bacterial cell cultures were grown to the early logarithmic phase (o.D. ${ }_{600}$ between 8 to 12) in MMS with $250 \mu \mathrm{M} \mathrm{L}-$ cysteine as sulphur source. Incubation took place in an Innova 4430 orbital shaker (New Brunswick, N J) at 300 rpm, using $25 \mathrm{ml}$ medium in a $250 \mathrm{ml}$ Erlenmeyer flask.

For each experiment, $5^{*} 10^{9}$ cells were pelletised by centrifugation, washed twice with MMS without added sulphur source (preheated to $30^{\circ} \mathrm{C}$ ) and resuspended in $5 \mathrm{ml}$ MMS. To this culture the sulphur source to be analysed was added at varying concentrations and incubated for an additional $30 \mathrm{~min}$.

For RNA isolation, about $10^{9}$ cells per culture were harvested by $15 \mathrm{sec}$ centrifugation at 16,000 g, followed by immediate removal of the supernatant and freezing of the pellet in liquid nitrogen. Preparation of total RNA from $C$. glutamicum cells was performed as described by Hüser $e t$ al. [38].

Primers for real-time RT-PCR were constructed to amplify intergenic regions of about $150 \mathrm{bp}$ length of the genes to be analysed, designated as *_lc1/2 [see Additional file 1]. The primers were designed using the Primer Designer 4.2 software (Sci Ed Software, Durham, NC) and were purchased from SIGMA-ARK (Darmstadt, Germany).

All real-time RT-PCR experiments were performed using a LightCycler (Roche, Mannheim, Germany) with the QuantiTect SYBR Green RT-PCR Kit (QIAGEN, Hilden, Germany). PCR mixes were set up and PCR was performed as described by Koch et al. [39]. All measurements were performed for two biological replicates per condition tested and with two technical replicates per biological replicate. The amounts of the mRNAs of the genes of the cluster were normalised on total RNA and the relative change in transcription rate was determined as $2^{-\Delta C P}$ with $\triangle \mathrm{CP}$ equal to the difference of the measured crossing points for the test and the control condition.

\section{Determination of transcriptional starts with the RACE method}

Total RNA was isolated from a C. glutamicum wild-type culture grown in MMS medium and subjected to sulphur starvation as described above. Primers binding downstream of the annotated translational starts of the cysI and fpr2 genes ( ${ }^{*}$ SP1-3 in Table 5) along with $1.5 \mu \mathrm{g}$ of total RNA were used for CDNA synthesis. The CDNA was then modified and amplified using the 5'/3' RACE kit (Roche Diagnostics) according to the supplier's protocol. The obtained PCR products were cloned into the pCRBlunt II-TOPO vector (Invitrogen, Karlsruhe, Germany) and transferred into E. coli DH10B cells [40]. At least four different clones per gene were selected for plasmid preparation and DNA sequencing (IIT Biotech, Bielefeld, Germany).

\section{Real-time monitoring of cell growth using nephelometry}

All strains to be tested (the wild-type strain and different mutants) were grown overnight in liquid $\mathrm{BH}$ medium in an Innova 4430 orbital shaker (New Brunswick, NJ) at $300 \mathrm{rpm}$. One $\mathrm{ml}$ of an o/n culture was pelletised, washed once with liquid MMES and transferred into a $100 \mathrm{ml}$ Erlenmeyer flask containing $10 \mathrm{ml}$ fresh, preheated MMES with addition of $500 \mu \mathrm{M}$ L-cysteine as sulphur source. After $\mathrm{o} / \mathrm{n}$ incubation in an orbital shaker at $300 \mathrm{rpm}$, one $\mathrm{ml}$ of the culture was again washed and transferred into $10 \mathrm{ml}$ MMES as described above. These cultures were incubated for 6 hours in an orbital shaker at $300 \mathrm{rpm}$.

For real-time growth monitoring, $1 \mathrm{ml}$ of each culture was pelletised and washed twice with MMES. For each test condition, $1 \mathrm{ml}$ MMES with addition of a sulphur source at varying concentrations was inoculated with washed cells of the strain to be tested for a final o.D. ${ }_{600}$ of 0.01. Per test condition, 6 wells of a 96-well Cellstar suspension culture plate (Greiner Bio-One, Essen, Germany) were filled with $100 \mu \mathrm{l}$ inoculated MMES per well. The plates were sealed with Breathe-Easy membrane (Diversified 
Biotech, Boston, MA) and growth was measured in a microplate nephelometer (BMG Lab Technologies, Offenburg, Germany). For these measurements, the parameters selected were: Incubation at $30^{\circ} \mathrm{C}, 50 \%$ laser intensity, gain of $86,2.5 \mathrm{~mm}$ laser focus point, $900 \mathrm{sec}$ orbital shaking with $3 \mathrm{~mm}$ shaking width, and measurement after each cycle with $0.2 \mathrm{sec}$ measurement time per well, $0.0 \mathrm{sec}$ positioning delay.

\section{GenBank/TrEMBL accession numbers}

All protein sequences from other organisms were obtained from the UniProt database [41]. The nucleotide sequences of all genes from C. glutamicum mentioned can be found via the genome entry (accession number [EMBL:BX927147]) with the ORF name as locus-tag. The amino acid sequences of the corresponding proteins are available under the following accession numbers: Cg3049 [EMBL:CAF20776], Cg3112 [EMBL:CAF20834], Cg3113 [EMBL:CAF20835], Cg3114 [EMBL:CAF20836], Cg3115 [EMBL:CAF20837], Cg3116 [EMBL:CAF20838], Cg3117 [EMBL:CAF20839], Cg3118 [EMBL:CAF20840], and Cg3119 [EMBL:CAF20841]. The accession numbers of the genome sequences used for comparative genomics are [EMBL:AE014295] (Bifidobacterium longum), [EMBL:BX248353] (C. diphtheriae), [EMBL:BA000035]

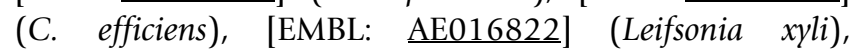
[EMBL:AE016958] (Mycobacterium avium), [EMBL:AL450380] (M. leprae), [EMBL:AL123456] (M. tuberculosis), [EMBL:AP006618] (Nocardia farcinica), [EMBL:AE017283] (Propionibacterium acnes), [EMBL:BA000030] (Streptomyces avermitilis), [EMBL:AL645882] (S. coelicolor), and [EMBL:BX072543] (Tropheryma whipplei).

\section{Bioinformatic analysis}

Sequence similarity-based searches with nucleotide and protein sequences were performed using BLAST, the Basic Local Alignment Search Tool [42] against the UniProt database [41]. Searches using profile Hidden Markov Models (HMMs) from the PFAM database [43] were done using the HMMer software package. Transmembrane domains were searched for using the TMHMM software [44] while for the detection of signal peptides SignalP [45] was used. Multiple alignments were done using DIALIGN 2 [46]. Search for conserved gene clusters was performed using the GECKO software [19] and TheSEED [20].

\section{Authors' contributions}

CR performed the bioinformatic analyses and carried out the mutational and transcriptional studies. DJK aided the mutational analysis and performed additional growth tests. DAR carried out transcriptional studies. AA performed the mapping of transcriptional start points. SM constructed the transposon library and identified a suitable mutant. AP aided in coordination and conceived of the design of tables and figures. JK conceived and coordinated this study. All authors read and approved of the final manuscript.

\section{Additional material}

\section{Additional File 1}

Supplementary Table S1.eps Supplementary Table S1 Oligonucleotides used in this study.

Click here for file

[http://www.biomedcentral.com/content/supplementary/1471-

2164-6-121-S1.eps]

\section{Acknowledgements}

$C R$ and DJK acknowledge a grant of the International NRW Graduate School in Bioinformatics and Genome Research. This work was further supported by Degussa AG, Germany. Sequence data for $B$. linens and $T$. fusca were produced by the US Department of Energy Joint Genome Institute http://www.jgi.doe.gov/.

\section{References}

I. Kredich NM: Biosynthesis of Cysteine. In Escherichia coli and Salmonella: Cellular and Molecular Biology Volume 2. 2nd edition. Edited by: Neidhardt FC, Curtis III R, Ingraham JL, Lin ECC, Low KB, Magasanik B, Reznikoff WS, Riley M, Schaechter M, Umbarger HE. Washington DC: ASM Press; 1996:5 14-527.

2. Williams SJ, Senaratne RH, Mougous JD, Riley LW, Bertozzi CR: 5'Adenosinephosphosulfate lies at a metabolic branch point in Mycobacteria. J Biol Chem 2002, 277(36):32606-326I5.

3. Mansilla MC, de Mendoza D: The Bacillus subtilis cysP gene encodes a novel sulphate permease related to the inorganic phosphate transporter (Pit) family. Microbiology 2000, | 46(4):8| 5-82I.

4. Sperling D, Kappler U, Wynen A, Dahl C, Trüper HG: Dissimilatory ATP sulfurylase from the hyperthermophilic sulfate reducer Archaeoglobus fulgidus belongs to the group of homo-oligomeric ATP sulfurylases. FEMS Microbiol Lett 1998, I 62(2):257-264.

5. Berndt C, Lillig CH, Wollenberg M, Bill E, Mansilla MC, de Mendoza $D$, Seidler A, Schwenn JD: Characterization and reconstitution of a 4Fe-4S adenylyl / phosphoadenylyl sulfate reductase from Bacillus subtilis. J Biol Chem 2004, 279(9):7850-7855.

6. van der Ploeg JR, Barone M, Leisinger T: Functional analysis of the Bacillus subtilis cysK and cysl genes. FEMS Microbiol Lett 200I, 20I:29-35.

7. Johansson $\mathrm{P}$, Hederstedt L: Organization of genes for tetrapyrrole biosynthesis in gram-positive bacteria. Microbiology 1999 , I 45(3):529-538.

8. Rückert C, Pühler A, Kalinowski J: Genome-wide analysis of the L-methionine biosynthetic pathway in Corynebacterium glutamicum by targeted gene deletion and homologous complementation. J Biotechnol 2003, I 04(I-3):2 I 3-228.

9. Kalinowski J, Bathe B, Bartels D, Bischoff N, Bott M, Burkovski A Dusch N, Eggeling L, Eikmanns BJ, Gaigalat L, Goesmann A, Hartmann M, Huthmacher K, Krämer R, Linke B, McHardy AC, Meyer F, Möckel B, Pfefferle W, Pühler A, Rey DA, Rückert C, Rupp O, Sahm H, Wendisch VF, Wiegräbe I, Tauch A: The complete Corynebacterium glutamicum ATCC 13032 genome sequence and its impact on the production of L-aspartate-derived amino acids and vitamins. J Biotechnol 2003, I 04(I-3):5-25.

10. Tauch A, Homann I, Mormann S, Rüberg S, Billault A, Bathe B, Brand S, Brockmann-Gretza O, Rückert C, Schischka N, Wrenger C, Hoheisel J, Möckel B, Huthmacher K, Pfefferle W, Puhler A, Kalinowski J: Strategy to sequence the genome of Corynebacterium glutamicum ATCC 13032: use of a cosmid and a bacterial artificial chromosome library. J Biotechnol 2002, 95:25-38. 
11. Mansilla MC, de Mendoza D: L-Cysteine Biosynthesis in Bacillus subtilis: Identification, Sequencing, and Functional Characterization of the Gene Coding for Phosphoadenylylsulfate Sulfotransferase. J Bacterial |997, I79(3):976-98|.

12. Nishio $Y$, Nakamura $Y$, Kawarabayasi $Y$, Usuda $Y$, Kimura E, Sugimoto S, Matsui K, Yamagishi A, Kikuchi H, Ikeo K, Gojobori T: Comparative Complete Genome Sequence Analysis of the Amino Acid Replacements Responsible for the Thermostability of Corynebacterium efficiens. Genome Res 2003, I3(7):1572-1579.

13. Wood DW, Setubal JC, Kaul R, Monks DE, Kitajima JP, Okura VK, Zhou Y, Chen L, Wood GE, Almeida NFJ, Woo L, Chen Y, Paulsen IT, Eisen JA, Karp PD, Bovee DS, Chapman P. Clendenning J, Deatherage G, Gillet W, Grant C, Kutyavin T, Levy R, Li MJ, McClelland E, Palmieri A, Raymond C, Rouse G, Saenphimmachak C, Wu Z, Romero P, Gordon D, Zhang S, Yoo H, Tao Y, Biddle P, Jung M, Krespan W, Perry M, Gordon-Kamm B, Liao L, Kim S, Hendrick C, Zhao ZY, Dolan M, Chumley F, Tingey SV, Tomb JF, Gordon MP, Olson MV, Nester EW: The genome of the natural genetic engineer Agrobacterium tumefaciens C58. Science 200I, 294(5550):23I7-2323.

14. Ermolaeva MD, Khalak HG, White O, Smith HO, Salzberg SL: Prediction of Transcription Terminators in Bacterial Genomes. J Mol Biol 2000, 30 I:27-33.

15. Rey DA, Nentwich SS, Rückert C, Koch DJ, Pühler A, Tauch A, Kalinowski J: The McbR repressor modulated by the effector substance $\mathrm{S}$-adenosylhomocysteine controls directly the transcription of a regulon involved in sulfur metabolism of Corynebacterium glutamicum ATCC 13032. Mol Microbiol 2005, 56(4):87I-887.

16. Kopriva $S$, Büchert T, Fritz G, Suter M, Benda R, Schünemann V, Koprivova A, Schürmann P, Trautwein AX, Kroneck PMH, Brunol C: The Presence of an Iron-Sulfur Cluster in Adenosine 5'-Phosphosulfate Reductase Separates Organisms Utilizing Adenosine 5'-Phosphosulfate and Phosphoadenosine 5'Phosphosulfate for Sulfate Assimilation. I Biol Chem 2002, 277(24):2|786-2|79|.

17. Fischer F, Raimondi D, Aliverti A, Zanetti G: Mycobacterium tuberculosis FprA, a novel bacterial NADPH-ferredoxin reductase. Eur J Biochem 2002, 269(I2):3005-30I3.

18. McLean KJ, Scrutton NS, Munro AW: Kinetic, spectroscopic and thermodynamic characterization of the Mycobacterium tuberculosis adrenodoxin reductase homologue FprA. Biochem J 2003, 372(2):3 17-327.

19. Schmidt T: GECKO: a tool for efficient gene cluster detection in prokaryotic genomes. Unpublished 2005 [http://bibiserv.tech fak uni-bielefeld de/download/tools/Gecko II html].

20. Overbeek R, Begley T, Butler RM, Choudhuri JV, Chuang HY, Cohoon M, Crecy V, de Crécy-Lagard V, Diaz N, Disz T, Edwards R, Fonstein M, Frank ED, Gerdes S, Glass EM, Goesmann A, Hanson A, Iwata-Reuyl D, Jamshidi N, Krause L, Kubal M, Larsen N, Linke B, McHardy AC, Meyer F, Neuweger H, Olsen G, Olson R, Osterman A, Portnoy V, Pusch GD, Rodionov DA, Rückert C, Steiner J, Stevens R, Thiele I, Vassieva O, Zagnitko O, Vonstein V: The Subsystems Approach to Genome Annotation and its Use In the Project to Annotate 1000 Genomes. Nucleic Acids Res 2005 in press.

21. Tauch A, Kaiser O, Hain T, Goesmann A, Wei??haar B, Albersmeier A, Bekel T, Bischoff N, Brune I, Chakraborty T, Kalinowski J, Meyer F, Rupp O, Schneiker S, Viehoever P, Pühler A: Complete genome sequence and anaylsis of the multiresistant nosocomial pathogen Corynebacterium jekeium $\mathrm{K} 4 \mathrm{I} \mathrm{I}$, a lipid-requiring bacterium of the human skin flora. J Bacteriol 2005, | 87(13):467|-4682.

22. Taiz L, Zeiger E: Plant Physiology Sunderland, MA: Sinauer Associates Inc; 2002.

23. Pátek M, Nesvera J, Guyonvarch A, Reyes O, Leblon G: Promoters of Corynebacterium glutamicum. J Biotechnol 2003, I04(I3):3II-323.

24. Hryniewicz MM, Sirko A, Pałucha A, Böck A, Danuta $H$ : Sulfate and thiosulfate transport in Escherichia coli K-12 - Identification of a gene encoding a novel protein involved in thiosulfate binding. J Bacteriol 1990, I72(6):3358-3366.

25. Sirko A, Hryniewicz MM, Hulanicka D, Böck A: Sulfate and thiosulfate transport in Escherichia coli K- 12 nucleotide sequence and expression of the cysTWAM gene cluster. J Bacteriol 1990, I 72(6):335I-3357.
26. Lee HS: Sulfur Metabolism and its Regulation. In Handbook of Corynebacterium glutamicum Ist edition. Edited by: Eggeling L, Bott M, Boca Raton. FL: Taylor \& Francis Group; 2005:35I-376.

27. Raux E, Leech HK, Beck R, Schubert HL, Santander PJ, Roessner CA, Scott Al, Martens JH, Jahn D, Thermes C, Rambach A, Warren MJ: Identification and functional analysis of enzymes required for precorrin-2 dehydrogenation and metal ion insertion in the biosynthesis of sirohaem and cobalamin in Bacillus megaterium. Biochem J 2003, 370(2):505-5I6.

28. Rey DA, Pühler A, Kalinowski J: The putative transcriptional repressor McbR, member of the TetR-family, is involved in the regulation of the metabolic network directing the synthesis of sulfur conatining amino acids in Corynebacterium glutamicum. J Biotechnol 2003, 103:5 I-65.

29. Brune I, Brinkrolf K, Kalinowski J, Pühler A, Tauch A: The individual and common repertoire of DNA-binding transcriptional regulators of Corynebacterium glutamicum, Corynebacterium efficiens, Corynebacterium diphtheriae and Corynebacterium jeikeium deduced from the complete genome sequences. BMC Genomics 2005, 6:86.

30. Koch D, Rückert C, Albersmeier A, Tauch A, Puhler A, Kalinowski J: The transcriptional regulator SsuR activates in the absence of sulphate the Corynebacterium glutamicum ssu and seu genes responsible for sulphonate utilization. Mol Microbiol 2005, 58(2):480-494

31. Vogel HJ, Bonner DM: Acetylornithinase of Escherichia coli: Partial purification and some properties. J Biol Chem 1956, 218:97-106

32. Sambrook J, Fritsch E, Maniatis T: Molecular cloning. A laboratory manual Edited by: 2. Cold Spring Harbour Laboratory Press; 1989.

33. Tauch A, Kirchner O, Löffler B, Götker S, Pühler A, Kalinowski J: Efficient Electrotransformation of Corynebacterium diphtheriae with a Mini-Replicon Derived from the Corynebacterium glutamicum Plasmid pGAI. Curr Microbiol 2002, 45(5):362-367.

34. Horton RM, Hunt HD, Ho SN, Pullen JK, Pease LR: Engineering hybrid genes without the use of restriction enzymes: gene splicing by overlap extension. Gene 1989, 77:61-68.

35. Schäfer A, Tauch A, Jäger W, Kalinowski J, Thierbach G, Pühler A: Small mobilizable multi-purpose cloning vectors derived from the Escherichia coli plasmids pK I 8 and pK I9: Selection of defined deletions in the chromosome of Corynebacterium glutamicum. Gene 1994, 145:69-73.

36. Tauch A, Götker S, Pühler A, Kalinowski J, Thierbach G: The 27.8kb R-plasmid PTET3 from Corynebacterium glutamicum encodes the aminoglycoside adenyltransferase gene cassette aadA9 and the regulated tetracycline efflux system Tet 33 flanked by active copies of the widespread insertion sequence IS6I00. Plasmid 2002, 48(2): I I7-I29.

37. Tauch A, Kassing F, Kalinowski J, Pühler A: The Corynebacterium xerosis composite transposon Tn5432 consists of two identical insertion sequences, designated ISI249, flanking the erythromycin resistance gene ermCX. Plasmid 1995, 34(2): || $|9-13|$.

38. Hüser AT, Becker A, Brune I, Dondrup M, Kalinowski J, Plassmeier J, Pühler A, Wiegräbe I, Tauch A: Development of a Corynebacterium glutamicum DNA microarray and validation by genomewide expression profiling during growth with propionate as carbon source. J Biotechnol 2003, I06(2-3):269-286.

39. Koch DJ, Rückert C, Rey DA, Mix A, Pühler A, Kalinowski J: The role of the ssu and seu genes of Corynebacterium glutamicum ATCC 13032 in the utilization of sulfonates and sulfonate esters as sulfur sources. Appl Environ Microbiol 2005, 71:6104-6114.

40. Grant SGN, Jessee J, Bloom FR, Hanahan D: Differential plasmid rescue from transgenic mouse DNAs into Escherichia coli methylation-restriction mutants. Proc Natl Acad Sci USA 1990 , 87( I 2):4645-4649.

4I. Bairoch A, Apweiler R, Wu CH, Barker WC, Boeckmann B, Ferro S, Gasteiger E, Huang H, Lopez R, Magrane M, Martin MJ, Natale DA, O'Donovan C, Redaschi N, Yeh LS: The Universal Protein Resource (UniProt). Nucleic Acids Res 2005, 33((Database issue)):DI54-159.

42. Altschul SF, Madden TL, Schäffer AA, Zhang J, Zhang Z, Miller W, Lipman DJ: Gapped BLAST and PSI-BLAST: a new generation of protein database search programs. Nucleic Acids Res 1997, 25(I7):3389-3402. 
43. Bateman A, Coin L, Durbin R, Finn RD, Hollich V, Griffiths-Jones $S$, Khanna A, Marshall M, Moxon S, Sonnhammer ELL, Studholme DJ, Yeats C, Eddy SR: The Pfam Protein Families Database. Nucleic Acids Res 2004, 32:DI38-DI4I.

44. Krogh A, Larsson B, von Heijne G, Sonnhammer ELL: Predicting Transmembrane Protein Topology with a Hidden Markov Model: Application to Complete Genomes. J Mol Biol 200I, 305(3):567-580.

45. Nielsen H, Engelbrecht J, Brunak S, von Heijne G: Identification of prokaryotic and eukaryotic signal peptides and prediction of their cleavage sites. Protein Eng 1997, 10:1-6.

46. Morgenstern B: DIALIGN 2: improvement of the segment-tosegment approach to multiple sequence alignment. Bioinformatics 1999, I5(13):211-218.

47. Jones-Mortimer MC: Mapping of structural genes for the enzymes of cysteine biosynthesis in Escherichia coli KI 2 and Salmonella typhimurium LT2. Heredity 1973, 3 I(2):213-22I.

48. Kirchner $O$, Tauch $A$ : Tools for genetic engineering in the amino acid-producing bacterium Corynebacterium glutamicum. J Biotechnol 2003, 104(I-3):287-299.

Publish with Bio Med Central and every scientist can read your work free of charge

"BioMed Central will be the most significant development for disseminating the results of biomedical research in our lifetime. "

Sir Paul Nurse, Cancer Research UK

Your research papers will be:

- available free of charge to the entire biomedical community

- peer reviewed and published immediately upon acceptance

- cited in PubMed and archived on PubMed Central

- yours - you keep the copyright

Submit your manuscript here:

http://www.biomedcentral.com/info/publishing_adv.asp
BioMedcentral 